Tjalling C. Koopmans Research Institute

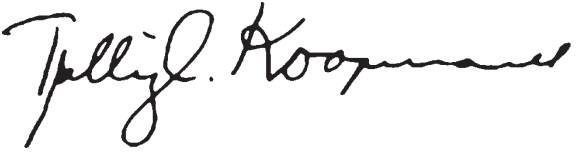

Discussion Paper Series nr: 09-15

\title{
Market liberalization in the European Natural Gas Market. The importance of capacity constraints and efficiency differences
}

Steven Brakman

Charles van Marrewijk

Arjen van Witteloostuijn 


\section{Tjalling C. Koopmans Research Institute Utrecht School of Economics Utrecht University}

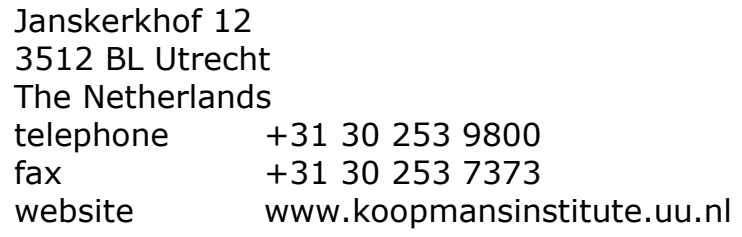

\section{How to reach the authors}

Please direct all correspondence to the first author.

\section{S. Brakman}

University of Groningen

Faculty of Economics

Department of International Economics and Business

P.O. Box 800

9700 AV Groningen

The Netherlands.

E-mail: s.brakman@rug.nl

Charles van Marrewijk*

Arjen van Witteloostuijn*^

*Utrecht University

Utrecht School of Economics

Janskerkhof 12

3512 BL Utrecht

The Netherlands.

E-mail: J.G.M.vanMarrewijk@uu.nl

$\wedge$ University of Antwerp

Faculty of Applied Economics

Department of Management

Antwerp Centre of Evolutionary Demography ( ${ }^{A}$ CED)

Prinsstraat 13

2000 Antwerpen

Belgium

E-mail: arjen.vanwitteloostuijn@ua.ac.be 
Utrecht School of Economics

Tjalling C. Koopmans Research Institute

Discussion Paper Series 09-15

\title{
Market liberalization in the European Natural Gas Market The importance of capacity constraints and efficiency differences
}

\author{
Steven Brakmana \\ Charles van Marrewijk ${ }^{b}$ \\ Arjen van Witteloostuijn ${ }^{\text {bc }}$
}

${ }^{a}$ Economics and Business Department University of Groningen

bUtrecht School of Economics Utrecht University

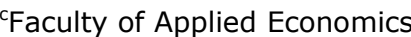
University of Antwerpen

July 2009

\begin{abstract}
In the European Union, energy markets are increasingly being liberalized. A case in point is the European natural gas industry. The general expectation is that more competition will lead to lower prices and higher volumes, and hence higher welfare. This paper indicates that this might not happen for at least two reasons. First, energy markets, including the market for natural gas, are characterized by imperfect competition and increasing costs to develop new energy sources. As a result, new entrants in the market are less efficient than incumbent firms. Second, energy markets, again including the market for natural gas, are associated with capacity constraints. Prices are determined in residual markets where the least efficient firms are active. This is likely to lead to price increases, rather than decreases.
\end{abstract}

Keywords: natural gas, capacity constraints, efficiency, market liberalization

JEL classification: Q4, L1, L7

\section{Acknowledgements}

Arjen van Witteloostuijn gratefully acknowledges the financial support from the Odysseus program of the Flemish Science Foundation (FWO). 


\section{Introduction}

Since the 1990s, market liberalization is a popular instrument in Europe to increase social welfare. The argument is that liberalized markets are associated with intensified competition. Economic theory predicts that more competition will produce lower prices and higher outputs (cf. Baumol, Panzar and Willig, 1982). ${ }^{1}$ Together, all this is to the benefit of consumers, both in the short and the long run, and hence is argued to increase social welfare. In this paper, we will reflect on this logic for the case of energy markets in general, and the European natural gas industry in particular. The point we want to make is not that economic theory is wrong, but rather that the kind of economic predictions the European Union (EU) is referring to are conditional. That is, it critically depends upon the idiosyncratic conditions of the market at hand whether or not liberalization will produce the intended outcomes. As we hope to illustrate below, energy and gas are likely not to be associated with the required conditions. If that is taken into account, then economic theory will predict that liberalization will not produce lower prices, but is rather likely to be associated with higher prices. ${ }^{2}$ Hence, if we are right, this implies not so much that economic theory is wrong, but rather that European policymakers are besides the mark.

If economic theory is to be used to understand competition in a particular industry, key is to first identify the specific conditions that characterize this particular industry. This is a well-established observation in the microeconomic theory of competition, also known as industrial organization, or IO (see, e.g., Tirole, 1988; van Witteloostuijn and Boone, 2006). For instance, if firms compete in prices (Bertrand)

\footnotetext{
${ }^{1}$ Strictly speaking, there is more to it than lower prices and higher outputs alone. Key is the distinction between so-called static vis-à-vis dynamic efficiency (cf. van Witteloostuijn, 1992). The former refers to prices and volumes, and the latter to process and product innovations. Here, we focus on static efficiency only.

${ }^{2}$ This implies that we focus on specific types of outcomes of the liberalization of the European natural gas market: prices and quantities. Another, and related, outcome variable is gas supply security. Wright (2005) offers a critical analysis of the liberalization-security link.
} 
rather than volumes (Cournot), cartel-like outcomes are much less likely to emerge. What policy intervention tends to do, which is certainly true for liberalization, is to change the very conditions that characterize the industry at hand. Hence, before we proceed, it is essential to identify the characteristics we believe are typical for the European natural gas market. We do so in Section 2. The next step is to diagnose what changes in which conditions the EU's intervention will imply. This is done in Section 3. We are then ready to develop an IO model of competition that features the industry's essential conditions, and to analyze what the intended changes in these conditions will do to prices and volumes, in Section 4. In Section 5, we systematically reflect on the model outcomes. Section 6 concludes.

\section{The European Gas Industry's Critical Conditions}

Starting point of any IO analysis that is expected to capture a real-world industry is the definition of the industry at hand. For our purposes, we limit attention to natural gas production, by and large. Of course, the gas industry is much more complicated than that. For instance, gas production is often in the hands of other parties than gas distribution. In principle, each part of the gas industry's value chain will feature its own competitive dynamics, which may differ from one Member State to the other (cf. Brakman, van Marrewijk and van Witteloostuijn, 2007). So, any IO model of competition in the gas industry, inevitably, involves simplifying assumptions that help to focus on the essence, given the question at hand. In our case, we believe that gas production is key to understand the effect of liberalization on competition in the EU's 
gas industry. ${ }^{3}$ After all, gas production generates the volumes with which other parties within the industry value chain have to work.

We believe that three conditions are essential in the European natural gas production industry - or gas industry, for short (cf. Clingendael International Energy Programme, 2008, and the many references therein). The first condition relates to IO's key distinction between price and output, or Bertrand and Cournot, competition. Of course, many industries feature aspects of both Bertrand and Cournot (Kreps and Scheinkman, 1983). This is not different in the gas industry. On the one hand, gas auction markets are clearly Cournot. On the other hand, gas delivery contracts involve Bertrand. However, the question is which competitive instrument takes center stage. Gas is, by and large, a homogeneous product that is brought to the market by not so many producers in large volumes. The number of producers is rather limited, with Algeria, the Netherlands, Norway and Russia as Europe's key players. In each country, a (partially) state-owned monopolist is in charge of gas production. Therefore, as do Egging and Gabriel (2006), we assume that the Cournot oligopoly model with product homogeneity best reflects the nature of the European gas (production) industry.

The second condition relates to the issue of efficiency. Gas suppliers can be ranked in terms of efficiency for at least three reasons. First, as in any industry, not all firms are equally efficient. For instance, a Western private-public joint venture such as Dutch Gasunie tends to be more efficient than a state-run monopolist such as Russian Gazprom. Second, the cost of gas production varies from one field to the other, depending upon the geophysical circumstances. In effect, gas production is associated with increasing costs to develop new gas fields. Third, local costs increase

\footnotetext{
${ }^{3}$ For a sophisticated example of a (simulation) model of the European natural gas market that distinguishes between different types of players, we refer to Egging, Gabriel, Holz and Zhuang (2008).
} 
with distance. With nearby gas fields depleting quickly, natural gas has to travel longer distances in the future. Figure 1 provides an example of the gas supply cost curve for the EU15, as predicted for 2020 (OME, 2002; Hafner, 2008).

[Insert Figure 1 about here]

Gas suppliers differ wildly in terms of efficiency (cf. Lochner and Bothe, 2009). Algerian Medgaz's efficiency is expected to be about $\$ 1.1$ per MBtu in 2020, whereas Russia's Shtockman supply is estimated to cost approximately $\$ 2.9$ per MBtu by 2020. Indeed, the efficiency gap is estimated to be of similar size in 2010 (OME, 2002: Diagram 5 on page 14). In effect, the data reveal a clear pattern. Using Figure 1's data, we can estimate the linear gas supply cost curve depicted in Figure 2.

[Insert Figure 2 about here]

On the basis of these estimates, a linear approximation explains about 98 per cent of the variance in marginal costs.

The third condition involves capacities. That is, gas production cannot be expanded indefinitely. By way of illustration, Table 1 lists the (expected) export potential of Europe's three major suppliers: Algeria, Norway, and Russia and Central Asia (Hafner, 2008).

\section{[Insert Table 1 about here]}

Not very surprisingly, this table reveals that each and every gas producer faces capacity constraints. For instance, the export capacity of Russia and Central Asia, Europe's largest supplier, is expected to be $166 \mathrm{bcm}$ in 2010 and $207 \mathrm{bcm}$ in 2030 . After all, natural gas is a nonrenewable natural resource, implying that the reserves are finite by definition. ${ }^{4}$ Although new reserves are discovered on an annual basis,

\footnotetext{
${ }^{4}$ Distribution capacity can imply an extra constraint. However, in principle, this constraint can be relaxed by building extra pipelines. Indeed, a variety of pipeline-building initiatives are either under way or negotiated about. However, in the end, the reserves capacity is binding. Moreover, pipeline development implies a costly and time-consuming investment.
} 
which partly explains the predicted increase in capacities, unavoidably gas producers will hit the upper limit of what they can produce, at some point. Note that the binding nature of the constraints is expected to increase over time for two reasons. First, the discovery and exploitation of new gas fields is characterized by decreasing returns, as is witnessed by Table 1's stepwise reduction in extra capacities per gas producer over time. Second, the opposite can be observed for European gas demand, which continues to grow in decades to come (Kjärstad and Johnsson, 2007; Remme, Blesl and Fahl, 2008). Total demand for gas in the European market is increasing. The main reason for this upward trend, ignoring business cycle-driven slumps, is the increasing demand from power plants as is revealed in Figure 3. The environmental advantage of gas over coal or oil-fuelled power plants is one of the main reasons for this trend.

$$
\text { [Insert Figure } 3 \text { about here] }
$$

The above suggests three critical conditions, which we translate into assumptions that will form the starting point for our modeling effort in Sections 4 and 5.

Assumption 1: The European natural gas industry is a Cournot (output) oligopoly.

Assumption 2: Europe's gas suppliers can be ranked in terms of increasing inefficiency.

Assumption 3: All of Europe's gas suppliers face a binding capacity constraint. 


\section{The EU's Gas Industry Liberalization Policy}

With the implementation of the Gas Directive (EU, 1998), the European gas market is moving toward further liberalization. This implies that the market for gas suppliers is changing drastically. Parallel to this development, the national gas markets in the Member States are being liberalized, though at different speeds. France, for example, is only reluctantly opening its domestic market to foreign competitive forces. In the Netherlands, the government has gone a step further than required by dismantling the so-called Gasgebouw ("gas building"). This was done in order to anticipate and facilitate the larger process of European natural gas market liberalization. The ultimate aim of liberalization of the gas market is to let demand and supply of gas determine the market-clearing equilibrium price so that efficiency will be increased, price will be reduced and customer choice will be expanded. Since different energy sources are to a certain extent substitutes, a certain degree of correlation between prices of different energy sources will always remain in place, reflecting the longerterm ability to substitute between them. However, as a consequence of liberalization, the close relationship between gas and oil prices should diminish over time.

In the EU, as indicated above, the EU Gas Directive (EU, 1998) has set out the path for liberalization of the gas industry by defining the regulatory space within which each Member State can search for a position. The key features of the Gas Directive are the following four.

1. There is a third-party access requirement. Member States must allow certain gas customers to buy gas from the supplier of their choice and to have it transported through the existing pipeline network at negotiated or regulated rates. Initially, this right will only be available to very large gas customers. For the first five years, only customers taking at least 25 million cubic metres of 
gas per year will be eligible. For the next five years, the eligibility set will be expanded to customers demanding at least 15 million cubic metres annually. In the final three years, the threshold reduces to 5 million cubic metres per annum.

2. Member States can choose between negotiated access and regulated access. Under negotiated access, individual customers enter into negotiations to determine the precise terms. Under regulated access, gas customers have a right of access on the basis of published regulated tariffs. Member States are required to "designate competent authorities, independent of the parties, with access to the internal accounts of the natural gas undertakings to settle access disputes expeditiously."

3. The Gas Directive also requires unbundling: "Natural gas undertakings are required to keep separate accounts in their internal accounting at least for their gas transmission, distribution, storage and consolidated non-gas activities as they would be required to do if the activities were carried out by separate undertakings." 5

4. Member States are allowed to impose public service obligations on gas utilities, which may relate to security of supply, regularity, quality and price of supplies, as well as to issues of environmental protection. Natural gas undertakings "may refuse access to their system on the basis of lack of capacity, or where the access to the system would prevent them from carrying out the public service obligations that are assigned to them by the Member State", or "if this would cause serious economic and financial difficulties with take-or-pay contracts".

\footnotetext{
${ }^{5}$ Note that EU's standpoint on unbundling has recently been relaxed.
} 
So, although the EU has launched its Gas Directive, it is not clear how its detailed implementation will work out in practice, as there is substantial room for manoeuvring at the national level. That is, each Member State can carefully balance the pros and cons of different regulatory options, which is quite likely to produce significant intra-EU diversity.

At present, the natural gas industry in Europe is largely characterized by national transmission monopolies, directly supplying about half of the total gas market, and a large number of regional distribution monopolies. The largest gas reserves that are directly connected to the EU-pipeline infrastructure are those of Algeria, Norway, Russia, the Netherlands, and the UK (with the UK losing ground quickly, as it is running out of its gas reserves). ${ }^{6}$ In contrast, the US industry involves a greater degree of vertical separation. In the US, there are a large number of gas producers, and the degree of integration between production and transmission pipelines is small. Many transmission pipelines are owned by wholesalers, which are subject to a complicated regulatory regime. The $\operatorname{OECD}(2000: 28)$ notes that "all gas prices have had a tendency to rise over the last decade in most OECD countries, they have declined in Canada and the UK, two countries which have liberated the gas industry during that time period." This observation offers a rationale for the EU's liberalization policy. However, can the British and Canadian historical experience be simply applied to the EU of the future?

Countries that had introduced competition in their natural gas markets by the late 1990s include Argentina, Australia, Canada, New Zealand, the UK and the US, all via third-party access to their pipeline and storage infrastructures. The experiences of those countries are, according to the IEA (2000: 40), that "regulatory reforms have

\footnotetext{
${ }^{6}$ This is ceteris paribus, given known reserves and the current cross-Europe pipeline infrastructure, and ignoring liquid gas import. In the longer run, the UK will be out of reserves, whilst the Middle East may find easier ways to penetrate the European market.
} 
yielded identifiable benefits in the form of increased customer choice, broader ranges as well as better quality of services, and lower end-user prices ... reliability of supply has been maintained ... open access has eliminated previously existing monopoly rents in gas supply ... and passed these cost savings, at least in part, to (eligible) consumers."

Yet, price volatility has increased, as measured by the day-to-day percentage difference in the price of the commodity, especially since prices can be very high when demand peaks. The IEA (2000: 45-46) also lists some problems. These concern "dynamic inefficiencies in the regulated system with system extension and maintenance of quality standards; [the] need for extremely complex and therefore costly metering and dispatching technology on the entire system in order to keep a minimum reliable basis for cost calculation; economic costs due to higher risk for potential long-term investors and risk of reduction in long-term investment; inefficiencies caused by arbitrary allocation of fixed costs or the unbundling of economies of scope; increased transaction costs; [and] high regulatory costs." In addition, the political accountability of regulating authorities may pose problems. The IEA (2000: 48) concludes that "[o]verall, the benefits in terms of enduser prices that have been achieved are the results of intense gas-to-gas competition and gas (commodity) trading. However, whether the access regulation and tarification itself has contributed to this, i.e. whether it has lowered the cost and the price of transport, is much less clear." Hence, even on the basis of experiences elsewhere in the world and an evaluation of an authority such as the IEA, it may well turn out that the unconditional belief in the dominant benefits of liberalization is naive. In the next sections, we add further arguments that may fuel this doubt. 
The bottom line is that the rhetoric of the EU claims that liberalization will push gas prices down due to the competitive pressure imposed upon the players in a freed marketplace. However, the proof of the pudding is in the eating, as the outcome of liberalization very much depends upon the gas industry's underlying conditions, and how these may change as a result of liberalization. In this respect, the gas price data presented by Robinson (2007) are revealing. In the 2000s, gas prices went up, rather than down. The model we will present next offers an explanation for this finding. It is important to note that our claim is not that competitive forces are not important, but that the structure of markets like those of the Gas markets is such that price increases are in practice likely.

\section{A Stylized Model of Competition}

\section{A general Cournot model}

We start by taking the conditions that characterize the EU's natural gas industry seriously. First, the EU gas market is best characterized by competition between a limited number of suppliers that primarily compete in output (Assumption 1), given the low number of gas-producing countries. Second, gas suppliers can be ranked in terms of increasing inefficiency (Assumption 2), due to technological reasons. Third, production of gas is limited by capacity constraints (Assumption 3), determined by the gas fields' reserves. To start with, we suggest a model framework of Cournot competition with capacity constraints.

In the first place, we cannot emphasize enough that, by its very structural nature, the natural gas industry is associated with imperfect competition, even after liberalization - i.e., a Cournot oligopoly. Furthermore, as we argued above, energy markets in general, and so also the natural gas market, are characterized by capacity 
constraints. These capacity constraints consist basically of two elements. First, in order to produce gas, new gas fields have to be developed, which is the most expensive part of gas production. Second, gas has to be distributed. The transport network has limited capacity (in terms of pipelines and hubs) that cannot be extended at will, but requires relatively large and time-consuming investments.

These two conditions combined ensure that the European gas market is best described by Cournot oligopoly competition with capacity constraints. Below, we analyze what this implies for the likely effect of liberalization. Specifically, we explore potential effects of liberalization by means of a limited number of illustrative scenario analyses, where liberalization is defined as an increase in the number of firms active in the market. In so doing, we can assess the likely impact of liberalization on static efficiency - i.e., prices and volumes. Our stylized model, by definition and by necessity, ignores many details. However, we believe that the model below offers ample opportunities to develop insight into the main (static efficiency) consequences of the liberalization process that is under way within the EU. It is our contention that the effects of capacity constraints are often neglected. As a consequence, the public tends to be disappointed by the effects of liberalization of the gas market, particularly, and energy market more generally.

Define $N$ as the number of firms ${ }^{7}$ active in the market in equilibrium, $i$ as the sub-index that indicates firm $i, K_{i}$ as the cost function given in Eq. (1) below, $F$ as fixed cost, $c$ as marginal cost, and $x$ as the quantity produced. ${ }^{8}$ So, liberalization implies a larger $N$. The linear demand function is given in Eq. (2), where $P$ is price and $X$ is total supply.

\footnotetext{
${ }^{7}$ Strictly speaking, given the logic of our model, "firms" refer to gas fields that differ in capacity and efficiency (see below). So, different firms / fields might be owned by the same company. This subtlety is not relevant in the context of our model.

${ }^{8}$ The equilibrium as specified only holds, of course, if all firms produce non-negative output and make non-negative profits. See below for more details on the restrictions this imposes.
} 
(1) $\quad K_{i}\left(x_{i}\right)=F_{i}+c_{i} x_{i}$

(2) $P=a-b X$

(3) $\quad X=\sum_{i} x_{i}$

Firms maximize their own profits, according to Eq. (4) below, by choosing their production level, taking the production level of other firms as given. The first-ordercondition is given in Eq. (5), where $x_{-i}$ means not firm $i$ production - that is, $x_{-i}=X-x_{i}:$ the production by all other firms in the market. The reaction curves can be written as Eq. (6), and solving gives Eq. (7).

(4) $\max _{x_{i}} \pi_{i}=P x_{i}-\left(F_{i}+c_{i} x_{i}\right)$

(5) $\quad x_{i}=\frac{1}{2 b}\left[a-b x_{-i}-c_{i}\right]$

(6) $\left[\begin{array}{ccccc}2 & 1 & \cdot & \cdot & 1 \\ 1 & 2 & \cdot & \cdot & 1 \\ \cdot & \cdot & \cdot & \cdot & \cdot \\ \cdot & \cdot & \cdot & 2 & 1 \\ 1 & 1 & \cdot & 1 & 2\end{array}\right]\left[\begin{array}{c}x_{1} \\ x_{2} \\ \cdot \\ x_{N-1} \\ x_{N}\end{array}\right]=\frac{1}{b}\left[\begin{array}{c}a-c_{1} \\ a-c_{2} \\ \cdot \\ a-c_{N-1} \\ a-c_{N}\end{array}\right]$

(7) $\left[\begin{array}{c}x_{1} \\ x_{2} \\ \cdot \\ x_{N-1} \\ x_{N}\end{array}\right]=\frac{1}{(N+1) b}\left[\begin{array}{ccccc}N & -1 & \cdot & \cdot & -1 \\ -1 & N & \cdot & \cdot & -1 \\ \cdot & \cdot & \cdot & \cdot & \cdot \\ \cdot & \cdot & \cdot & N & -1 \\ -1 & -1 & \cdot & -1 & N\end{array}\right]\left[\begin{array}{c}a-c_{1} \\ a-c_{2} \\ \cdot \\ a-c_{N-1} \\ a-c_{N}\end{array}\right]$

Firm $i$ 's solution, the market equilibrium price and production level are given in 


$$
\begin{aligned}
x_{i} & =\left(a-N c_{i}+\sum_{j \neq i} c_{j}\right) /(N+1) b, \quad i=1, . ., N \\
X & =\left(N a-\sum_{j} c_{j}\right) /(N+1) b \\
P & =\left(a+\sum_{j} c_{j}\right) /(N+1)
\end{aligned}
$$

Note that, in equilibrium, we have $\left(P-c_{i}\right)=b x_{i}$. So, profits for firm $i$ are given by $\pi_{i}=b x_{i}^{2}-F_{i}-$ i.e., they are proportional to the square of output minus fixed costs.

\section{Rising inefficiency without capacity constraints}

By way of steppingstone, we first assume that capacity constraints are absent. This implies that, in principle, each and every firm could serve the whole market. We are now ready to introduce Assumption 3, inter-firm efficiency differences, by introducing the following more specific cost structure, reflecting the rise in marginal production costs: $K_{i}\left(x_{i}\right)=F+(i \cdot 2 \lambda+1) \kappa x_{i}$. The idea behind this specification is that we can rank firms according to (marginal) efficiency. The parameter $\lambda$ reflects the increase in inefficiency as measured by marginal costs if another firm becomes active in the market (expressed as [twice] the percentage of the marginal costs of a hypothetical firm 0 ), while $\kappa$ is an inverse measure of the general efficiency of the market. Depending on market conditions or the maturity of the market, these parameters can change. Consequently, we have

(9) $\quad \sum_{j=1}^{N} c_{j}=\sum_{j=1}^{N}(j 2 \lambda+1) \kappa=N \kappa[1+(N+1) \lambda]$,

which can be substituted in Eq. (8) to give 


$$
\begin{aligned}
& x_{i}=\frac{(a-\kappa)}{(N+1) b}+\frac{\lambda \kappa(N-2 i)}{b} \geq 0, \quad i=1, . ., N \\
& X=\frac{N(a-\kappa)}{(N+1) b}-\frac{N \lambda \kappa}{b} \\
& P=\left(a+\sum_{j} c_{j}\right) /(N+1)=\frac{a+N \kappa}{N+1}+N \lambda \kappa
\end{aligned}
$$

This gives Proposition 1.

Proposition 1 (Rising inefficiency results in price increases): In the absence of capacity constraints, rising inefficiency (positive $\lambda$ ) leads to a higher market price. $^{9}$

It follows trivially from Eq. (10) that markets characterized by increasing inefficiency of (additional) firms (that is, positive values of $\lambda$ ) raise price relative to markets in which these inefficiencies are absent. For the gas market, these increasing inefficiencies are a fact of life (cf. Figure 2). The interesting question is what the likely effect of liberalization in such markets will be. One can expect a balance between increasing inefficiency that leads to price increases (Proposition 1) versus more competition that - in principle - leads to price decreases. Proposition 2a says that the competition effect dominates.

\footnotetext{
${ }^{9}$ Our model implies, as a by-product of the Cournot oligopoly with product homogeneity assumption, that market prices within the EU converge. Indeed, Robinson (2007) reports evidence in support of such convergence. Moreover, his Figure 1 (on page 2348) reveals increasing prices in the 2000s - a stylized fact in line with our model outcome as well (see below).
} 
Proposition $2 a$ (Rationality of competition policy): In the absence of capacity constraints, market liberalization (an increase in the number of firms) leads to higher output and lower price if the following condition is fulfilled:

$$
(N+1)^{2}<(a-\kappa) / \lambda \kappa .
$$

Proposition 2a follows directly from differentiating the market Eq. (10) with respect to $N$. From Eq. (2) it follows that if market output rises, the market price decreases. The proposition states that the (square of) the number of firms weighted by the incremental increase in inefficiency cannot be too high. So, competition policy works in the sense that increased competition reduces market price, but only up to a point. Potentially, if the (marginal) costs of taking additional gas fields into production become too high, price will increase despite competition. Whether or not this effect is economically important is discussed below. Eq. (10) also explains the opposition of incumbent firms against market liberalization, as is reflected in Proposition $2 b$.

Proposition $2 b$ (Competition policy and incumbent firms): In the absence of capacity constraints, market liberalization (a rise in the number of firms from $N_{0}$ to $N_{1}$ ) leads to lowers sales and profits for incumbent firms if, and only if, the following condition holds: $\left(N_{0}+1\right)\left(N_{1}+1\right)<(a-\kappa) / \lambda \kappa$.

Proposition $2 \mathrm{~b}$ follows from the equilibrium sales for individual firms in Eq. (10). Let the number of firms in the market rise from $N_{0}$ to $N_{1}$. Let $x_{i, j}$ be firm $i$ 's sales if there are $N_{j}$ firms active in the market. From Eq. (10) we have 


$$
\begin{aligned}
& x_{i, 0}=\frac{(a-\kappa)}{\left(N_{0}+1\right) b}+\frac{\lambda \kappa\left(N_{0}-2 i\right)}{b}>\frac{(a-\kappa)}{\left(N_{1}+1\right) b}+\frac{\lambda \kappa\left(N_{1}-2 i\right)}{b}=x_{i, 1} \\
& \Leftrightarrow \frac{(a-\kappa)}{\left(N_{0}+1\right)}-\frac{(a-\kappa)}{\left(N_{1}+1\right)}>\lambda \kappa\left(N_{1}-N_{0}\right) \\
& \Leftrightarrow \frac{(a-\kappa)\left(N_{1}-N_{0}\right)}{\left(N_{0}+1\right)\left(N_{1}+1\right)}>\lambda \kappa\left(N_{1}-N_{0}\right) \\
& \Leftrightarrow \quad\left(N_{1}-N_{0}\right)<(a-\kappa) / \lambda \kappa
\end{aligned}
$$

Note that this condition is the discrete counterpart of the condition in Proposition 2a on market price. So, if competition policy results in an increase in the number of firms, the sales of incumbent firms and the market price falls, resulting in lower profits for the incumbent firms. Evidently, as a firm's operating profits are proportional to the square of output, which is falling as inefficiency (marginal cost) rises, the profits of the new entrants are lower than for the incumbent firms.

This brings us to the issue of the viability of firms. Since we arranged the firms in increasing inefficiency (rising marginal costs), we know that sales fall as the index $i$ increases. If there are $N$ firms active in the market, we refer to the $N^{\text {th }}$ firm as the 'marginal' firm. If output is positive for the marginal firm, it is also positive for all other firms. Since equilibrium profits are $\pi_{i}=b x_{i}^{2}-F_{i}$, the impact of fixed costs on firm viability is simple and well-known (i.e., it strengthens the positive output criterion). Hence, we follow Neary (2007) in putting fixed costs equal to zero for simplicity from now on. This gives Proposition 3.

Proposition 3 (Viability of the marginal firm): In the absence of capacity constraints, in a market with $N$ firms, the marginal firm's output $x_{N}$ is positive if, and only if, the following condition holds: $(N+1) N<(a-\kappa) / \lambda \kappa$. 
Substituting $i=N$ in the firm output expression of Eq. (10) gives

$$
x_{N}=\frac{(a-\kappa)}{(N+1) b}-\frac{\lambda \kappa N}{b}>0 \Leftrightarrow \frac{(a-\kappa)}{(N+1) b} \geq \frac{\lambda \kappa N}{b} \Leftrightarrow(N+1) N<\frac{a-\kappa}{\lambda \kappa}
$$

Evidently, the condition given in Proposition 3 is slightly weaker than that given in Proposition 2a for a rise in the number of firms to lower market price. This substantially limits the possible range for which a rise in the number of firms might lead to a higher market price, as illustrated in Figure 4.

\section{[Insert Figure 4 about here]}

For a numerical example, Figure 4 illustrates the quadratic function of $N$ determining if the price level falls if $N$ rises (Proposition 2a) and the quadratic function of $N$ determining if output of the marginal firm is positive. Clearly, the curves are almost identical. In fact, the difference between the points of intersection with the horizontal axis depends solely on the value of $(a-\kappa) / \lambda \kappa$, which ranges from zero to infinity. The maximum intersection difference of one firm is provided for by $(a-\kappa) / \lambda \kappa=0$. As $(a-\kappa) / \lambda \kappa \rightarrow \infty$ (i.e., as $\lambda \downarrow 0)$, the difference in intersection becomes zero. In principle, therefore, a rise in the number of firms always leads to a lower market price, except possibly for the market entry of the last firm. ${ }^{10}$ These considerations allow us to determine the equilibrium number of firms if markets are liberalized. This provides Proposition 4.

\footnotetext{
${ }^{10}$ In addition to the difference in intersection with the horizontal axis of the two curves as illustrated in Figure 4, which depends only on $(a-\kappa) / \lambda \kappa$, we are dealing with the integer constraint and the price level if there are $N$ firms and $N-1$ firms, respectively. The price level depends not only on $(a-\kappa) / \lambda \kappa$, but also on the individual parameter set $(a, k, \lambda)$. Several attempts so far have not provided an example in which the price level actually rises as the last firm with positive output enters. Clearly, a small fixed cost would also eliminate this theoretical possibility.
} 
Proposition 4 (Equilibrium number of firms): If market liberalization leads to firm entry as long as profits are positive, the equilibrium number of firms without capacity constraints, $N^{*}$ say, is given by

$N^{*}=\operatorname{int}(-0.5+0.5 \sqrt{1+4(a-\kappa) / \lambda \kappa})$.

The equilibrium number of firms $N^{*}$ rises if (a) the market size as measured by a rises, (b) the market inefficiency as measured by $\kappa$ falls, and (c) the marginal cost increment as measured by $\lambda$ falls.

The equilibrium number of firms follows trivially from solving the viability condition in Proposition 3 and imposing the integer constraint. The impact of the various market forces on the equilibrium number of firms is straightforward. Without capacity constraints, liberalization of the European natural gas market is likely to produce what the EU is claiming it will produce: a lower price. The question is, though, whether this conclusion can be sustained after the introduction of our Assumption 3: capacity constraints.

\section{Rising inefficiency with capacity constraints}

The model introduced above is a stylized description of the European natural gas market (or of any other market with rising marginal costs). The model gives intuitively plausible results. However, as noted in Section 2, we argue that this benchmark provides an incomplete description of energy markets, generally, and gas markets, particularly, as the above specification fails to capture capacity constraints. Energy sources, including natural gas, are found in specific geographical places, each of which faces capacity constraints. New fields can only be developed at increasing marginal costs. These constraints can have technical reasons, leading to a maximum 
amount of energy that can be harvested in a given time period. The constraints can be of political origin as well. For instance, the Dutch government does not want to deplete the Slochteren gas field too quickly in order to safeguard future gas supply in the Netherlands. For whatever reason, capacity restraints are important. This is why we will now introduce Assumption 3, to explore the consequences of capacity restraints vis-à-vis the results derived from the without-constraints model.

Figure 5 illustrates our line of reasoning. For illustration purposes, we introduce two firms in the market only. As above, the second firm has higher marginal costs (MC) than the first firm, indicated by the line $M C$ firm 2 that lies above $M C$ firm 1. So, firm 1 has a competitive advantage over firm 2 . If firm 1 is faced with a capacity constraint, $\bar{x}$, two situations can occur: the constraint is binding, or it is not. In the latter case, the analysis above holds for two firms. To the contrary, Figure 5 illustrates what happens if the constraint is binding. Firm 1 can supply $\bar{x}$ units of goods before the constraint becomes binding. The less efficient firm 2 is clever enough to realize firm 1's capacity constraint. Consequently, it recognizes that the market price is now determined in the residual market, indicated in Figure 5 by the leftward shift of market demand by the amount $\bar{x}$.

[Insert Figure 5 about here]

Note that firm 2 is a monopolist in the residual market (i.e., it does not face competition from capacity-constrained firm 1), and acts accordingly. The point of intersection of firm 2's marginal cost curve with the residual market's marginal revenue curve determines the optimal output level for firm 2 (here 5 units). The price level in the residual market (4.5) is equal to the price level in the market as a whole (as firm 1 is able to charge the same price). Although, at face value, there are two firms active in the market, the market price is actually determined by the monopoly 
behavior of firm 2 in the residual market. Consequently, the competitive pressure in the market is less severe than one would think by focusing on the number of active firms in the market per se.

Naturally, it must be profitable for both firms to be active in the market. As firm 2 is the least efficient of the two firms, this implies that firm 2's profits must be positive. If, on the contrary, firm 2's profits are not positive, then firm 1 will be a monopolist in the market (again, also in this case the - optimal - output of the monopolist can or cannot be restricted by the capacity restraint). The illustration in Figure 5 already suggests that markets with capacity restraints can be different from markets as analyzed above, because prices are determined in residual markets by firms that have higher marginal costs. In general, one expects higher prices than in markets that do not face firm-level capacity restraints. We now turn to the formal analysis of supply-constrained firms in a more general Cournot competition setting.

Suppose that there are, again, $N$ firms active in the market and that the first $n$ (most efficient) firms face an identical capacity constraint $\bar{x} \cdot{ }^{11}$ Residual market demand is given by

(2') $\quad P=a-b n \bar{x}-\sum_{j=n+1}^{N} x_{j}$

If we define $a_{n} \equiv a-b n \bar{x}$ and $N_{n}=N-n$, we can use the general Cournot solution given in Eq. (8) to determine equilibrium price and production in the residual market. This gives

\footnotetext{
${ }^{11}$ We introduce this simplifying assumption to keep the calculus tractable. This assumption does not affect the main outcomes of our model.
} 


$$
\begin{aligned}
x_{i} & =\left(a_{n}-N_{n} c_{i}+\sum_{j \neq i} c_{j}\right) /\left(N_{n}+1\right) b, \quad i=1, . ., N_{n} \\
\text { (8') } \quad X_{n} & =\left(N_{n} a_{n}-\sum_{j} c_{j}\right) /\left(N_{n}+1\right) b \\
P_{n} & =\left(a_{n}+\sum_{j} c_{j}\right) /\left(N_{n}+1\right)
\end{aligned}
$$

The cost structure if $n$ firms are capacity-constrained and $N_{n}$ are active in the residual market $^{12}$ is given for firm $i$ by $F+(i \cdot 2 \lambda+1+2 n \lambda) \kappa x_{i}, \quad i=1, . ., N_{n}$. From this, we have

(9') $\quad \sum_{j=1}^{N_{n}} c_{j}=\sum_{j=1}^{N_{n}}(j 2 \lambda+1+2 n \lambda) \kappa=N_{n}(1+2 n \lambda) \kappa+\lambda N_{n}\left(N_{n}+1\right) \kappa$

Now define $\kappa_{n} \equiv \kappa(1+2 n \lambda)$, and insert this and Eq. (9') in Eq. ( $\left.8^{\prime}\right)$ to arrive at ${ }^{13}$

$$
\begin{aligned}
x_{i} & =\frac{\left(a_{n}-\kappa_{n}\right)}{\left(N_{n}+1\right) b}+\frac{\lambda \kappa\left(N_{n}-2 i\right)}{b} \\
\left(10^{\prime}\right) \quad X_{n} & =\frac{N_{n}\left(a_{n}-\kappa_{n}\right)}{\left(N_{n}+1\right) b}-\frac{N_{n} \lambda \kappa}{b} \\
P_{n} & =\frac{a_{n}+N_{n} \kappa_{n}}{N_{n}+1}+N_{n} \lambda \kappa
\end{aligned}
$$

Note the similarities and differences between Eqs (10) and (10'). This implies that the propositions - and solutions - derived in our benchmark model have a natural correspondence to the model introduced here. We will therefore not restate the

\footnotetext{
${ }^{12}$ Note that $i$ is the index in the residual market. So, it corresponds to firm $i+n$ in the original market.

${ }^{13}$ In the formulae, sometimes $\kappa_{n}$ is used, and sometimes $\kappa$. This is not a mistake.
} 
propositions of the without-constraints model for the model with capacity restraints. Table 2 compares the equilibrium outcome of the two models.

[Insert Table 2 and Figure 6 about here]

Figure 6 illustrates the impact of the firm-level capacity constraint Assumption 3 on the rising inefficiency model equilibrium. In both panels, the horizontal axis shows the capacity constraint faced by individual firms. Panel $a$ illustrates the effects of capacity constraints on market price and output, while panel $b$ shows the effects of capacity constraints on the number of firms active in the market. For comparison, the panels also indicate price and quantity (panel $a$ ) and the number of firms (panel $b$ ) in the model without capacity constraints. Going from right to left in the panels, we observe the following:

1. If the capacity constraint is not binding for any firm, the equilibria in both models coincide.

2. As the restraint becomes tighter, initially one and subsequently more firms become capacity-constrained. This lowers competitive pressure, and thus raises the market price and lowers the quantity produced, initially without affecting the number of firms active in the market.

3. As the constraint becomes tighter still, new entry into the market by less efficient firms becomes viable. At the same time, more firms become capacity-constrained. Consequently, competitive pressure is determined in the residual market by an ever-decreasing number of firms (see panel $b$; the difference between the dashed and solid line). This further raises market price and lowers market quantity (panel $a$ ). 
Before continuing with a more general discussion of the capacity-constrained rising inefficiency model, our main findings are summarized in Proposition 5.

Proposition 5 (Capacity constraints and (residual) competition): Introducing capacity constraints in markets with rising inefficiency results in (a) higher market price and lower market output and (b) less competitive pressure (fewer firms active in the residual market), despite (potentially) more firms in the market as a whole.

We focus attention on proving that capacity constraints lead to higher market prices and lower quantities as this suffices to simply illustrate the second point of Proposition 5 (lower competitive pressure, despite potentially more firms in the market) by means of an example, as we have done above. For ease of reference, Eq. (11) restates the equilibrium market price $P$ without capacity constraints and $P_{n}$ the market price if the $n$ most efficient firms are capacity-constrained.

$$
\begin{aligned}
& P=\frac{a+N \kappa}{N+1}+N \lambda \kappa ; \quad P_{n}=\frac{a_{n}+N_{n} \kappa_{n}}{N_{n}+1}+N_{n} \lambda \kappa, \\
& \text { where } a_{n} \equiv a-b n \bar{x}, \quad N_{n} \equiv N-n, \quad \text { and } \quad \kappa_{n} \equiv \kappa(1+2 n \lambda)
\end{aligned}
$$

Let $n=1$, and determine under which condition $P_{1} \geq P$. Then,

$$
\begin{array}{ll}
P_{1}=\frac{a-b \bar{x}+(N-1) \kappa(1+2 \lambda)}{N}+(N-1) \lambda \kappa \geq \frac{a+N \kappa}{N+1}+N \lambda \kappa=P & \Leftrightarrow \\
\frac{(N+1)[a-b \bar{x}+(N-1) \kappa(1+2 \lambda)]}{N(N+1)} \geq \frac{N(a+N \kappa)}{N(N+1)}+\frac{N(N+1) \lambda \kappa}{N(N+1)} & \Leftrightarrow
\end{array}
$$




$$
\begin{array}{ll}
(N+1)[a-b \bar{x}+(N-1) \kappa(1+2 \lambda)] \geq N(a+N \kappa)+N(N+1) \lambda \kappa & \Leftrightarrow \\
(N+1) a-(N+1) b \bar{x}+(N+1)(N-1) \kappa(1+2 \lambda) \geq N a+N^{2} \kappa+N(N+1) \lambda \kappa & \Leftrightarrow \\
a-(N+1) b \bar{x}+\left(N^{2}-1\right) \kappa+\left(N^{2}-1\right) 2 \lambda \kappa \geq N^{2} \kappa+N(N+1) \lambda \kappa & \Leftrightarrow \\
a-\kappa+N^{2} \lambda \kappa-2 \lambda \kappa-N \lambda \kappa \geq(N+1) b \bar{x} & \Leftrightarrow \\
(a-\kappa)+(N-2)(N+1) \lambda \kappa \geq(N+1) b \bar{x} & \Leftrightarrow \\
\bar{x} \leq \frac{(a-\kappa)}{(N+1) b}+\frac{(N-2) \lambda \kappa}{b}=x_{0}, &
\end{array}
$$

where the last equality follows from Eq. (10). Therefore, if firm 1 is effectively capacity-constrained, the equilibrium market price is higher. ${ }^{14}$ To complete the proof, we show that a similar procedure can be used inductively such that in general $P_{n+1} \geq P_{n}$ if firm $n+1$ is effectively capacity-constrained. Note that $a_{n+1}=a_{n}-b \bar{x}, \quad N_{n+1}=N_{n}-1$, and $\kappa_{n+1}=\kappa_{n}+2 \lambda \kappa$. To determine a condition such that $P_{n+1} \geq P_{n}$ we use equation (11):

$$
\begin{array}{ll}
P_{n+1}=\frac{a_{n+1}+N_{n+1} \kappa_{n+1}}{N_{n+1}+1}+N_{n+1} \lambda \kappa \geq \frac{a_{n}+N_{n} \kappa_{n}}{N_{n}+1}+N_{n} \lambda \kappa=P_{n} & \Leftrightarrow \\
\frac{a_{n}-b \bar{x}+\left(N_{n}-1\right)\left(\kappa_{n}+2 \lambda \kappa\right)}{N_{n}}+\left(N_{n}-1\right) \lambda \kappa \geq \frac{a_{n}+N_{n} \kappa_{n}}{N_{n}+1}+N_{n} \lambda \kappa & \Leftrightarrow \\
\left(N_{n}+1\right)\left[a_{n}-b \bar{x}+\left(N_{n}-1\right)\left(\kappa_{n}+2 \lambda \kappa\right)\right] \geq N_{n}\left[a_{n}+N_{n} \kappa_{n}\right]+\left(N_{n}+1\right) N_{n} \lambda \kappa & \Leftrightarrow \\
\left(N_{n}+1\right) a_{n}-\left(N_{n}+1\right) b \bar{x}+\left(N_{n}+1\right)\left(N_{n}-1\right)\left(\kappa_{n}+2 \lambda \kappa\right) \geq & \Leftrightarrow \\
N_{n} a_{n}+N_{n}^{2} \kappa_{n}+\left(N_{n}+1\right) N_{n} \lambda \kappa & \Leftrightarrow \\
a_{n}-\left(N_{n}+1\right) b \bar{x}+\left(N_{n}^{2}-1\right) \kappa_{n}+\left(N_{n}^{2}-1\right) 2 \lambda \kappa \geq+N_{n}^{2} \kappa_{n}+\left(N_{n}+1\right) N_{n} \lambda \kappa & \Leftrightarrow \\
a_{n}-\kappa_{n}+N_{n}^{2} \lambda \kappa-2 \lambda \kappa-N_{n} \lambda \kappa \geq\left(N_{n}+1\right) b \bar{x} & \Leftrightarrow \\
\left(a_{n}-\kappa_{n}\right)+\left(N_{n}-2\right)\left(N_{n}+1\right) \lambda \kappa \geq\left(N_{n}+1\right) b \bar{x} & \Leftrightarrow \\
\bar{x} \leq \frac{a_{n}-\kappa_{n}}{N_{n}+1}+\frac{\left(N_{n}-2\right) \lambda \kappa}{b} & \Leftrightarrow
\end{array}
$$

From equation (10) it follows that $P_{n+1} \geq P_{n}$ if firm $n+1$ is effectively capacityconstrained.

\footnotetext{
${ }^{14}$ Indeed, one can note that the unconstrained market equilibrium price can also be written as $P_{0}$.
} 
So, the introduction of capacity constraints (Assumption 3) in a Cournot competition model (Assumption 1) with a rising inefficiency supply rank (Assumption 2) changes the market outcomes completely. Without capacity constraints, we had price decreases if $N$ increases, as claimed by the EU; in contrast, with capacity constraints, a larger $N$ will generate price increases, as prices are determined in the residual market. Note that our model is silent about the dynamic effects of liberalization. For one, our model ignores all kinds of issues related to dynamic competition, such as innovation and security. Moreover, with free entry, price will increase less than it would do without liberalization. The point we want to make here, though, is twofold:

1. The number of firms alone is not very informative about the extent of competition, as many other market conditions may frustrate the ceteris paribus competition-increasing effect of a larger number of competitors.

2. Indeed, with the "right" assumptions in place, an increasing number of firms may generate higher rather than lower prices, as is likely to be the case in the EU's natural gas industry.

Before concluding, we would like to discuss a few interesting by-product results of our model in the next section.

\section{Further Discussion}

\section{Individual firm production}

Figure 7 illustrates the impact of firm-level capacity constraints on the production level of individual firms. By the (linear) ordering of inefficiency and in the absence of capacity constraints, firm 1 produces most, followed by firm 2, equidistantly followed 
by firm 3, et cetera. This continues until the (profit) viability restraint becomes binding. In the example of Figure 7, this leads to 11 firms active in the market, as illustrated in the right-hand part of the figure.

\section{[Insert Figure 7 about here]}

Going from right to left in the Figure 7 (as the capacity restraints become tighter), we note that there are three groups of firms:

1. The most efficient firm 1 is confronted with a monotonic decline in output once the restraint is binding and becomes tighter.

2. There is a range of intermediately efficient firms $i$ (in the example, firms 2-11) for which the output level rises as the capacity constraint becomes tighter for its more efficient competitors $\{1, . ., i-1\}$, until the constraint becomes binding for the firm itself. From then on, output declines monotonically with the tighter constraint.

3. There is a range of inefficient firms $i$ (in the example, firms 12-72; only firms 12-15 are shown in the figure) for which production is initially not viable (so output is zero), then becomes viable, from which point on production rises as the capacity constraint becomes tighter for its more efficient competitors $\{1, . ., i-1\}$, until the constraint becomes binding for the firm itself. From then on, output declines monotonically with the tighter constraint.

Conclusion: tighter capacity restraints ensure that a larger share of market output is produced by less efficient firms, which drives up market price and lowers output. 


\section{Individual firm profit}

The owners of individual firms are, of course, more interested in the bottom line that is, in profit rather than production levels. Using the same example as above, Figure 8 illustrates the profit levels of the individual firms. In the absence of capacity constraints and without fixed costs, profits are proportional to the square of equilibrium production $\left(\pi_{i}=b x_{i}^{2}\right)$, implying that the respective profit levels at the right-hand side of the figure are not linear, but rather based on a quadratic function.

[Insert Figure 8 about here]

Going from right to left in the Figure 8 (as the capacity restraints become tighter), we note that there are now (roughly) four groups of firms:

1. The most efficient firm 1 is confronted with a monotonic decline in profits if the constraint becomes more binding.

2. There is a range of intermediately efficient firms $i$ (in the example, firms 2-7) that are confronted with a rise in profits as the capacity constraint becomes tighter for its more efficient competitors $\{1, . ., i-1\}$, until the constraint becomes binding for the firm itself. From then on, profits decline with the tighter constraint. ${ }^{15}$

3. There is a range of less efficient firms $i$ (in the example, firms 8-11) that are confronted with rising profits as the capacity constraint becomes tighter for its more efficient competitors $\{1, . ., i-1\}$, even if the constraint becomes binding for them, up to a firm-specific optimal point. Clearly, there is no incentive for these firms to invest in capacity within this range.

\footnotetext{
${ }^{15}$ Although its profits are maximized at the point where the capacity constraint becomes binding for firm 7, its profits do not decline monotonically from then on as the constraint tightens (due to integer considerations) - hence the loose term "roughly" in parentheses in the main text.
} 
4. There is a range of inefficient firms $i$ (in the example, firms 12-72; only firms 12-15 are shown in the figure) for which production is initially not viable (so output is zero), then becomes viable, from which point on profits rise as the capacity constraint becomes tighter for its more efficient competitors $\{1, . ., i-1\}$, even if the constraint becomes binding for them, up to a firmspecific optimal point.

Conclusion: except for the most efficient firm, tighter capacity restraints imply higher firm profits for firm-specific ranges of capacity restraints. Within that range, firms have no incentive to invest in capacity. In general, the incentive to expand capacity is higher for the most efficient firms.

\section{Rising market demand}

The impact of rising market demand on price, quantity and the number of active firms is illustrated in Figure 9. Here, the economic intuition is fairly straightforward. If market demand is low (at the left-hand side of the figure), the capacity constraint is not binding, implying that the equilibrium of the with-constraints model is identical to that of without-constraints one. As demand rises, the production level increases and so does the price level. At this stage, the rising price level reflects two separate forces. On the one hand, a rise in demand parameter $a$ leads to a linear increase in price given the number of firms $N($ as $\partial P / \partial a=1 /(N+1))$. On the other hand, the rising demand level allows for the entry of new firms, which increases competition and lowers price (see Proposition 2a). The net effect is a concave increase in price, as can be seen in Figure 9a. As demand rises further, the capacity constraint becomes binding for the most efficient firms (first firm 1, then firms 1 and 2, et cetera). From then on, the 
reduced competitive pressure in the residual market for the unconstrained firms leads to significantly higher prices (and thus lower quantities) than in the absence of capacity constraints. Note that the number of firms in the residual market is virtually constant (five firms, in the example), as is clear from Figure $9 \mathrm{~b}$.

$$
\text { [Insert Figure } 9 \text { about here] }
$$

\section{Cost inefficiency}

Figure 10 illustrates the impact of generally rising costs as measured by the inefficiency parameter $\kappa$. At the intuitively obvious level, in the absence of capacity constraints, rising costs (higher inefficiency) leads to higher prices, lower quantities, and less competitive pressure as the number of firms declines.

[Insert Figure 10 about here]

At the less intuitively obvious level, three important observations can be made:

1. The equilibrium market deviation of price and quantity between the model with and without capacity constraints is maximized at intermediate levels of cost inefficiency, as can be seen in Figure 10a. When cost inefficiency is either very high or very low, the equilibrium of the with-constraints coincides with that of the without-constraints one. With very high costs, the market is ultimately served by an unconstrained monopolist. With very low costs, the number of firms active in the market increases in conjunction with competitive pressure to ultimately ensure that no firm is capacity-constrained.

2. The equilibrium number of constrained firms is maximized at lowintermediate levels of cost inefficiency, as is visualized in Figure 10b.

3. There can be equilibria where all firms active in the market are capacity-

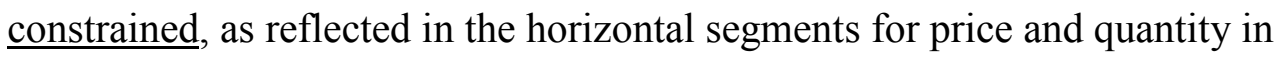
Figure 10a. In these cases, residual market demand is so low that entry and 
production by the next most efficient firm is not viable and price is determined by the production level of all the constrained firms (hence the horizontal segments). In these cases, the total number of firms coincides with the number of constrained firms in Figure 10b.

The appendix shows that the impact of the cost increase parameter $\lambda$ on the market equilibrium is quite similar to that of the general inefficiency parameter $\kappa$.

\section{Conclusion}

In this paper, we illustrate that it is very likely that liberalization of the European natural gas industry will not lead to lower prices and higher quantities, but will rather be associated with higher prices and lower volumes. This conclusion follows from selecting, we believe, the appropriate model from the many available in IO economics. In the end, after all, it is the behavior of market players that determines the outcomes (cf. Ellis, Bowitz and Roland, 2000). Understanding the likely impact of a policy intervention in the marketplace requires, first, the careful identification of the key conditions that characterize the market at hand. Only then, the appropriate model can be selected. We argue that the European natural gas market is characterized by three key conditions: (1) imperfect competition of the Cournot oligopoly type with

product homogeneity; (2) (potential) gas suppliers that can be ranked from high to low efficiency; and (3) capacity constraints for each and every (potential) gas supplier. Starting from this set of three essential conditions, we develop an IO model of competition that reveals that subsequent entry of more inefficient firms will induce higher prices, rather than lower ones, contrary to what the EU's rhetoric wants the public to believe. In terms of static efficiency, for sure, the net effect of liberalization 
is likely to be more moderate price increases than the ones that would occur without liberalization. However, notwithstanding market liberalization, price will increase rather than increase.

Of course, we presented a stylized model of competition. This is inevitable in this type of work. Although we believe that our stylized representation captures the essence of the real-world natural gas market in Europe, further work can focus on developing more fine-grained models of competition. For example, we ignored the chain nature of this industry, with separate markets for production, transportation, storage, trade and distribution. As we argued above, this is justified in our case because the key constraints and the key inefficiencies are located in the production part of the natural gas industry's value chain. However, to really understand the subtle dynamics in the European natural gas industry - and other energy markets, for that matter - and the differential impact of (de)regulation, other IO models may be developed that can better handle other issues, such as the rent distribution across the different parts of the value chain, the impact of different liberalization regimes across Member States, or the higher-level EU - supply country bargaining (see, e.g., Jamasb, Pollitt and Triebs, 2008, on gas transmission). A final future research issue we would like to emphasize is the move toward more dynamic models, introducing elements of innovation and investment (cf. Castro-Rodriquez, Marín and Siotis, 2009). Doing so would endogenize capacity constraints and efficiency levels, two of the key determining features of the European natural gas industry.

\section{References}

Baumol, W.J., J.C. Panzar and R.D. Willig (1982), Contestable Markets and the Theory of Industry Structure, New York: Harcourt, Brace, Jovanovich. 
Brinkhorst, L.-J., Minister van Economische Zaken ("Ministry of Economic Affairs") (2003), Herstructurering Gasgebouw ("Restructuring the Gas Building”), Brief aan de Tweede Kamer, Vergaderjaar 2003-2004, 28 109, \# 5, The Hague: Tweede Kamer (Second Chamber).

Castro-Rodriguez, F., P.L. Marín and G. Siotis (2009), "Capacity Choices in Liberalised Electricity Markets”, Energy Policy, 37: 2574-2581.

Clingendael International Energy Programme (2008), The Gas Supply Outlook for Europe: The roles of pipeline gas and $L N G$, The Hague: Clingendael.

Egging, R.G. and S.A. Gabriel (2006), "Examining Market Power in the European Natural Gas Market”, Energy Policy, 34: 2762-2778.

Egging, R.G., S.A. Gabriel, F. Holz and J. Zhuang (2008), “A Complementarity Model for the European Natural Gas Market”, Energy Policy, 36: 2385-2414.

Ellis, A., E. Bowitz and K. Roland (2000), “Structural Change in Europe’s Gas Markets: Three scenarios for the development of the European gas market to 2020", Energy Policy, 28: 297-309.

EU (1998), Directive 98/30/EC of the European Parliament and of the Council of 22 June 1998 (the First Gas Directive).

Hafner, M. (2008), “Long-Term Natural Gas Demand and Supply Outlook for Europe: Import potential, infrastructure needs and investment risk mitigation”, Paper presented at the FEEM seminar, October 15 2008, Milan.

IEA (2000), World Energy Outlook 2000, Paris, OECD.

Jamasb, T., M. Pollitt and T. Triebs (2008), "Productivity and Efficiency of US Gas Transmission Companies: A European regulatory perspective”, Energy Policy, 36: 3398-3412. 
Kjärstad, J. and F. Johnsson (2007), "Prospects of the European Gas Market”, Energy Policy, 35: 869-888.

Kreps, D.M. and J.A. Scheinkman (1983), "Quantity Precommitment and Bertrand Competition Yield Cournot Outcomes”, Bell Journal of Economics, 14: 326-337. Lochner, S. and D. Bothe (2009), "The Development of Natural Gas Supply Costs to Europe, the United States and Japan in a Globalizing Gas Market: Model-based analysis until 2030", Energy Policy, 37: 1518-1528.

Neary, P.J. (2007), “Cross-border Mergers as Instruments of Comparative Advantage”, Review of Economic Studies, 74: 1229-1257.

OECD (2000), Promoting Competition in the Natural Gas Industry, Paris: DAFFE/CLP(2000)18.

OME (Observatoire Mediterraneen de l'Energie) (2002), Assessment of Internal and External Gas Supply Options for the EU: Evaluation of the supply costs of new natural gas supply projects to the EU and an investigation of related financial requirements and tools, Nanterre: OME.

Remme, U., M. Blesl and U. Fahl (2008), "Future European Gas Supply in the Resource Triangle of the Former Soviet Union, the Middle East and Northern Africa”, Energy Policy, 36: 1622-1641.

Robinson, T. (2007), “Have European Gas Prices Converged? ”, Energy Policy, 35 : $2347-2351$

Tirole, J. (1998), The Theory of Industrial Organization, Cambridge MA: MIT Press. Witteloostuijn, A. van (1992), “Theories of Competition and Market Performance: Multimarket competition and the source of potential entry", De Economist, 140: 109-139. 
Witteloostuijn, A. van and C. Boone (2006), “A Resource-Based Theory of Market Structure and Organizational Form”, Academy of Management Review, 31: 409426.

Witteloostuijn, A. van, S. Brakman and C. van Marrewijk (2007), "Welfare Distribution Effect of a Price Reduction in the Dutch Gas Transport Market: A scenario analysis of regulatory policy, market form and rent allocation”, Energy Policy, 35: 62996308.

Wright, P. (2005), "Liberalisation and Security of Gas Supply in the UK", Energy Policy, 33: $2272-2290$. 


\section{Appendix}

The figure below illustrates that the impact of the cost increase parameter $\lambda$ on the market equilibrium is quite similar to that of the general inefficiency parameter $\kappa$.

Figure A: Impact of cost increase parameter $\lambda$
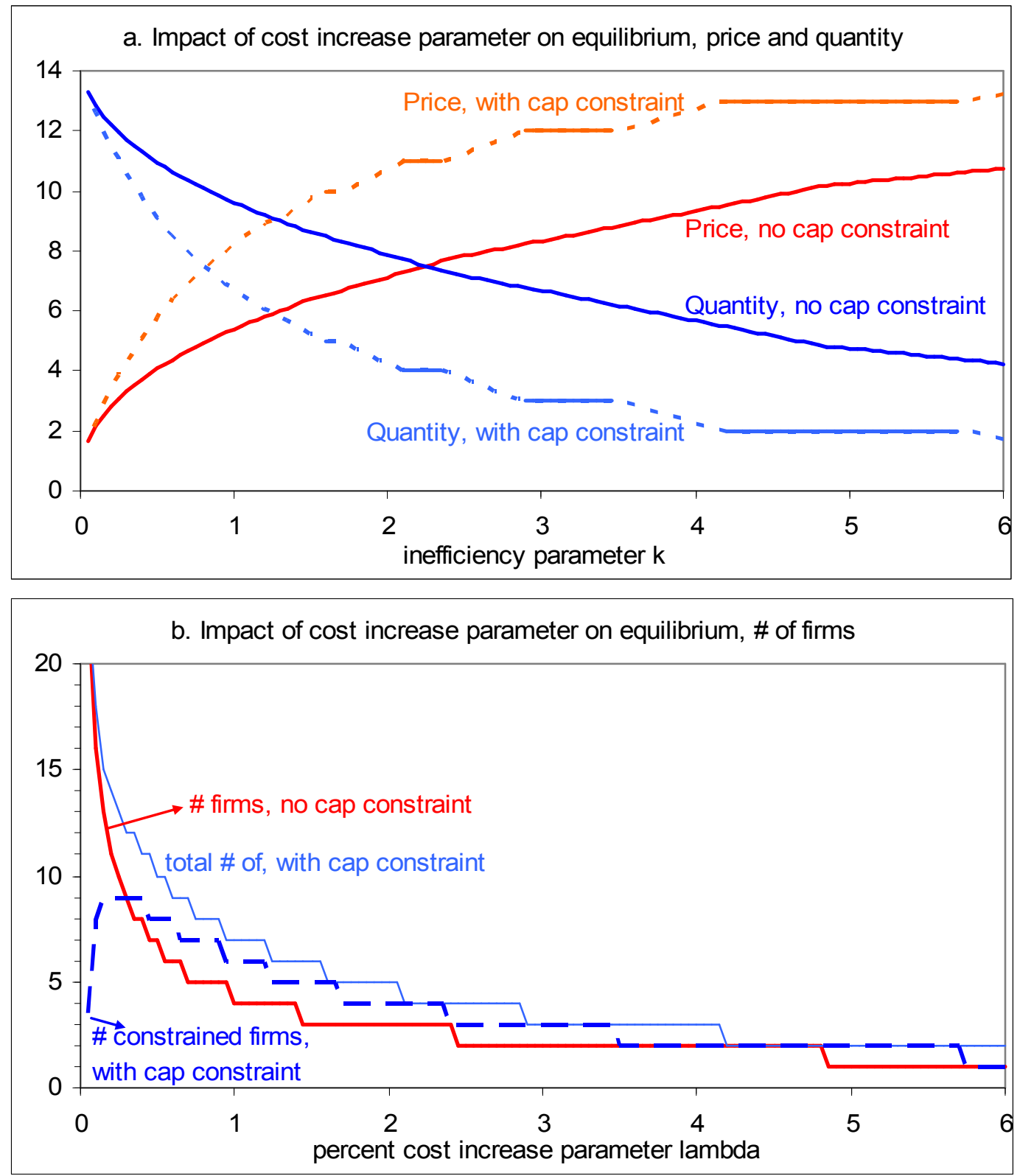

Parameters: $\bar{x}=1 ; b=1 ; F=0 ; a=15 ; \kappa=0.5$. Note that the four horizontal parts indicated by solid sections for price and quantity with capacity constraints in panel $a$ identify sections where all firms active in the market are capacity-constrained. 
Table 1: Future gas export potential for Europe

\begin{tabular}{|l|c|c|c|c|}
\hline \multicolumn{1}{|c|}{ Countries } & Year 2005 & Year 2010 & Year 2020 & Year 2030 \\
\hline & $304 \mathrm{bcm}$ & $447 \mathrm{bcm}$ & $619 \mathrm{bcm}$ & $695 \mathrm{bcm}$ \\
\hline Algeria & 57 & 81 & 110 & 115 \\
\hline Norway & 81 & 94 & 95 & 100 \\
\hline Russia and Central Asia & 139 & 166 & 196 & 207 \\
\hline
\end{tabular}

Source: Hafner (2008). 
Table 2: Rising costs solution with and without capacity restraints

\begin{tabular}{|c|c|c|}
\hline \multirow{2}{*}{$\begin{array}{l}\text { No capacity constraint } \\
P=\frac{a+N \kappa}{N+1}+N \lambda \kappa\end{array}$} & \multicolumn{2}{|l|}{ Capacity constraint for $n$ firms } \\
\hline & $P_{n}=\frac{a_{n}+N_{n} \kappa_{n}}{N_{n}+1}+N_{n} \lambda \kappa$ & \\
\hline$X=\frac{N(a-\kappa)}{(N+1) b}-\frac{N \lambda \kappa}{b}$ & $X_{n}=\frac{N_{n}\left[a_{n}-\kappa_{n}\right]}{\left(N_{n}+1\right) b}-\frac{\lambda N_{n} \kappa}{b}$ & \\
\hline$x_{i}=\frac{(a-\kappa)}{(N+1) b}+\frac{\lambda \kappa(N-2 i)}{b} \geq 0$ & $x_{i}=\left\{\begin{array}{c}\bar{x}, \\
\frac{\left(a_{n}-\kappa_{n}\right)}{\left(N_{n}+1\right) b}+\frac{\lambda \kappa\left(N_{n}-2(i-n)\right)}{b}\end{array}\right.$ & $\begin{array}{l}i=1, . ., n \\
i=n+1, . ., N\end{array}$ \\
\hline$N^{*}=\operatorname{int}\left(\frac{-1+\sqrt{1+4(a-\kappa) / \lambda \kappa}}{2}\right)$ & $N_{n}^{*}=\operatorname{int}\left(\frac{-1+\sqrt{1+4\left(a_{n}-\kappa_{n}\right) / \lambda \kappa}}{2}\right)$ & \\
\hline
\end{tabular}


Figure 1: Predicted gas supply cost curve for the EU15 in 2020 (source: Hafner, 2008)

\section{Gas Supply Cost Curve to EU15 for 2020 (Additional Volumes)}

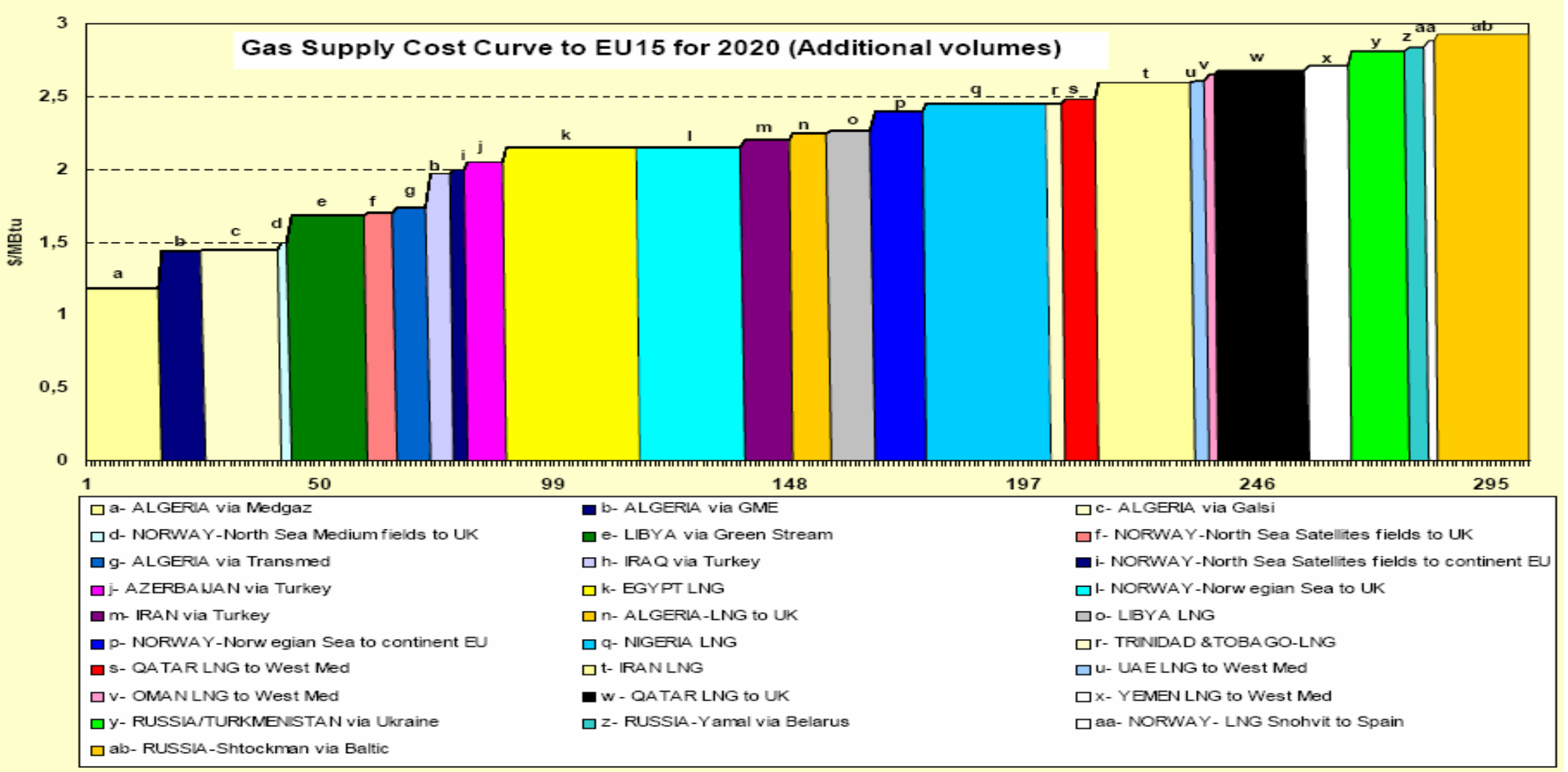


Figure 2: Estimated gas cost curve for the EU15 in 2020

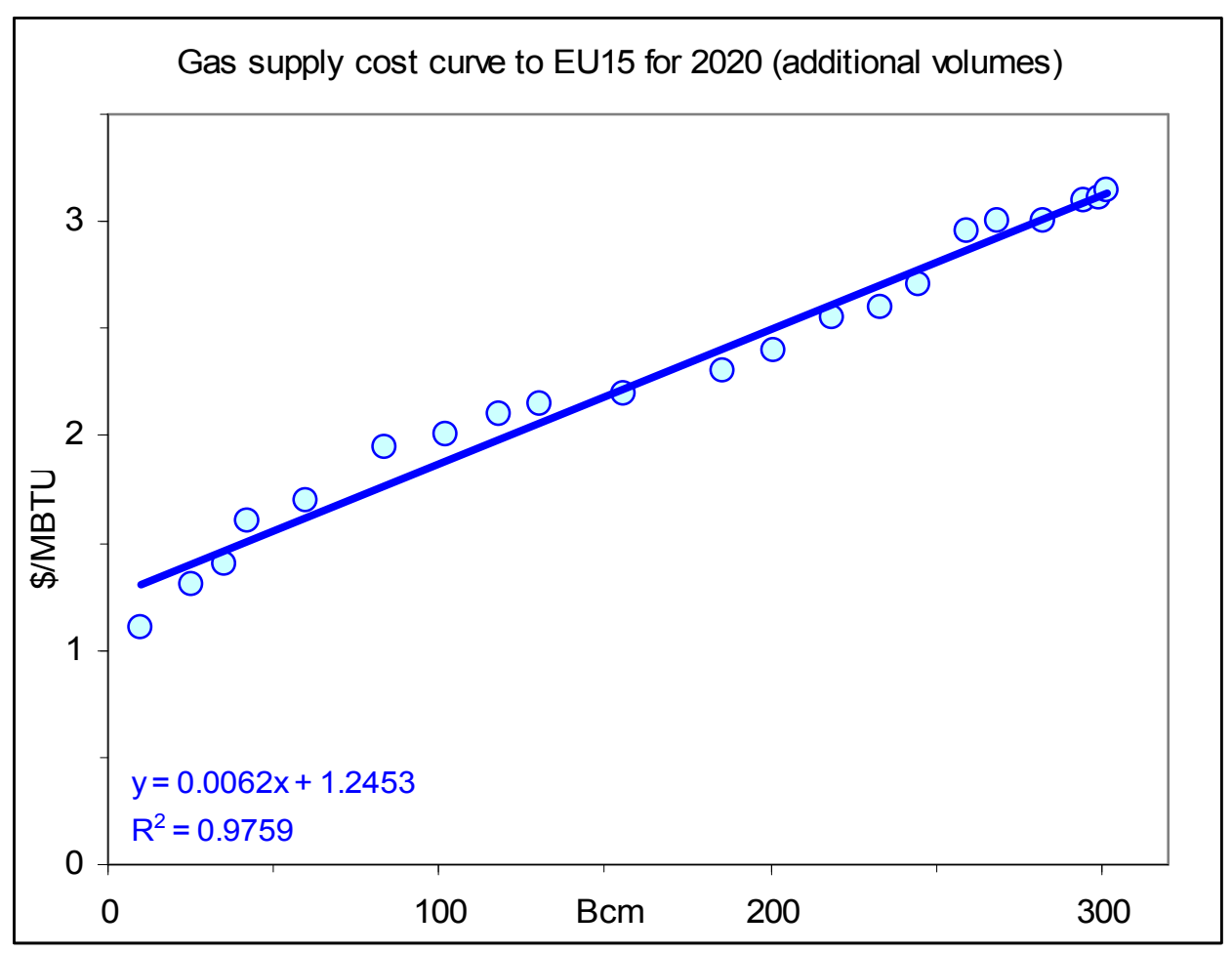


Figure 3: European demand for natural gas

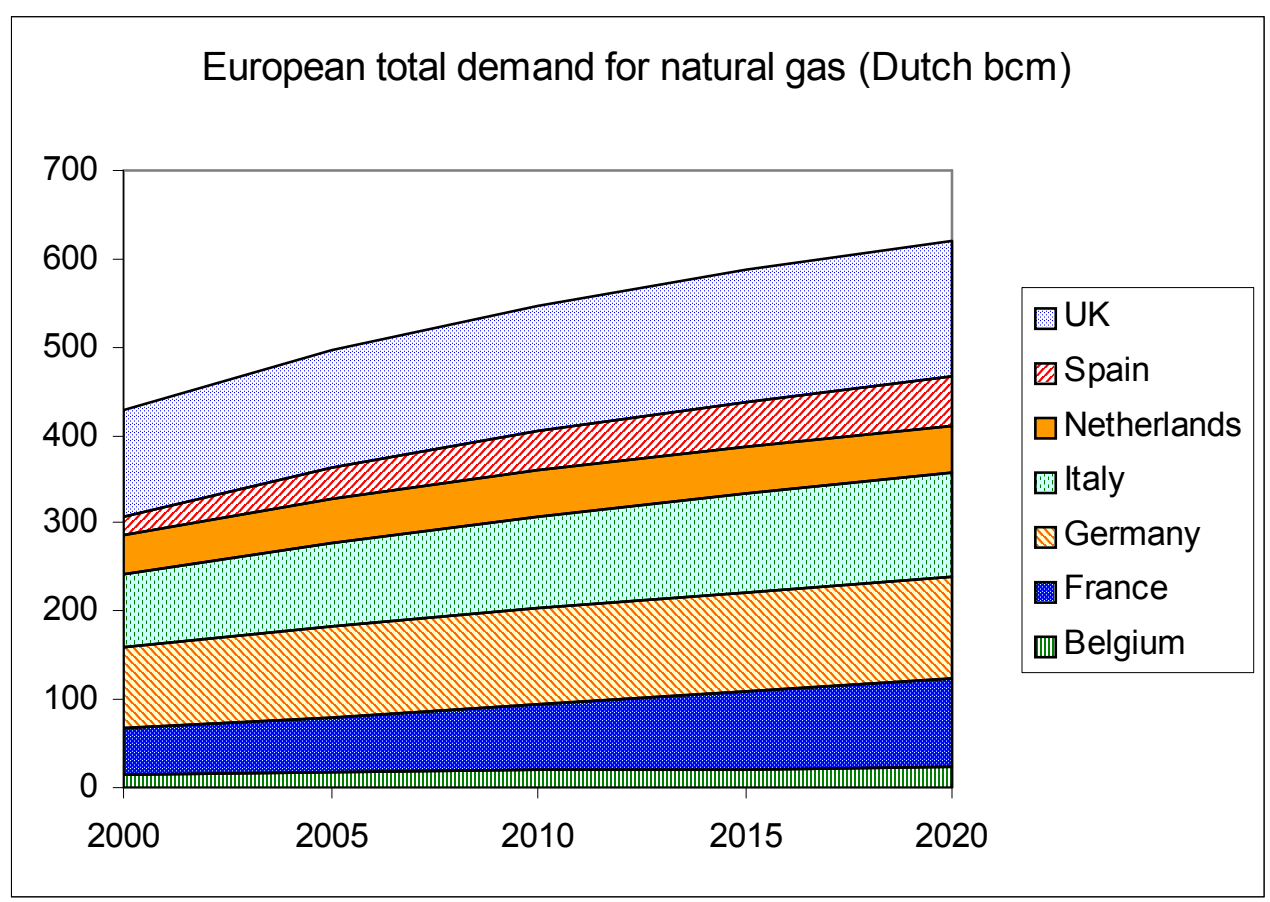

Source: DRI WEFA 2002 European Gas Storage Study (2002).

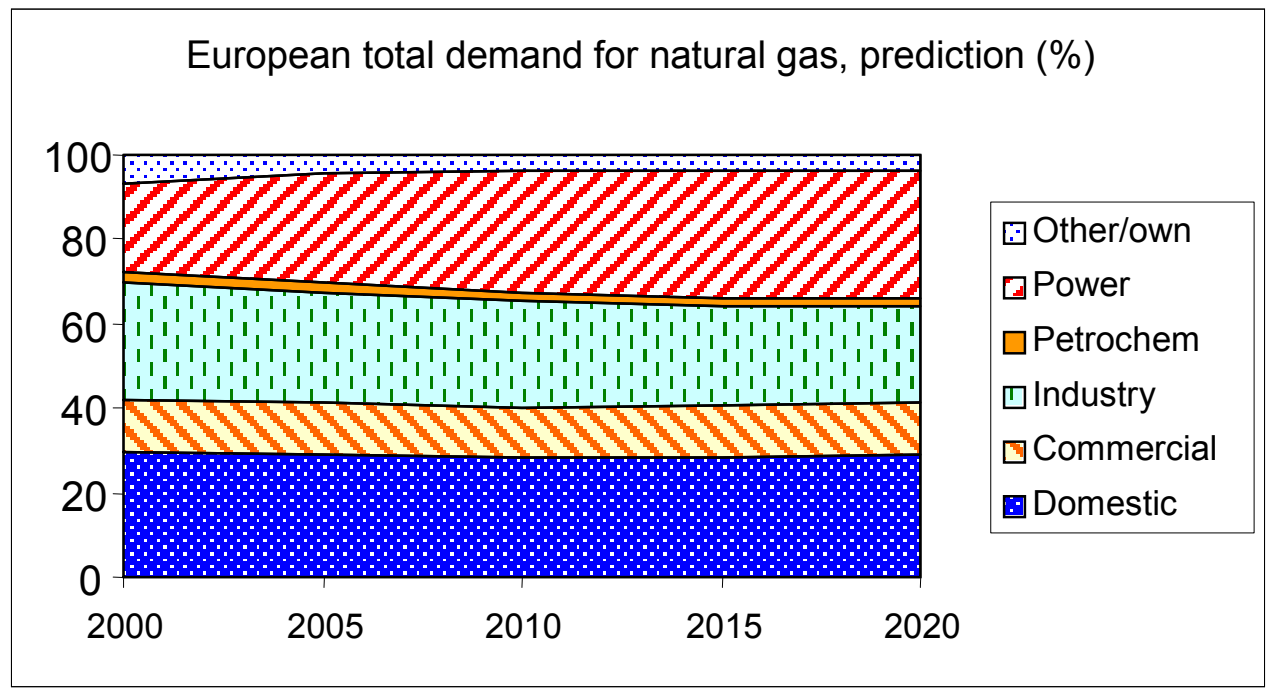

Source: DRI WEFA 2002 European Gas Storage Study (2002). 
Figure 4: Falling market prices and positive production

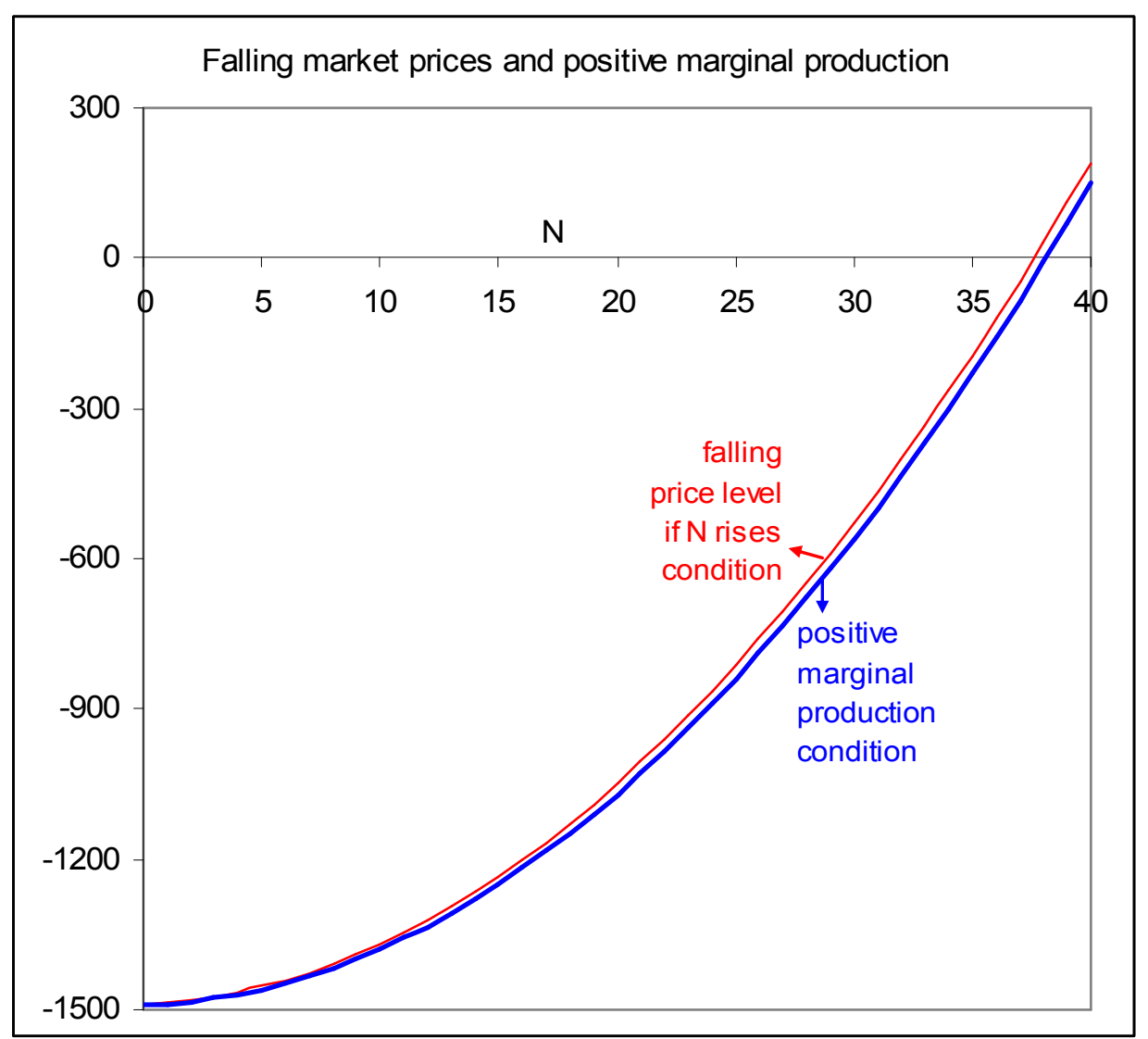

Parameters: $a=15 ; b=1 ; F=0 ; \kappa=0.1 ; \lambda=0.1$. 
Figure 5: Market price if firm 2 is a monopolist in the residual market

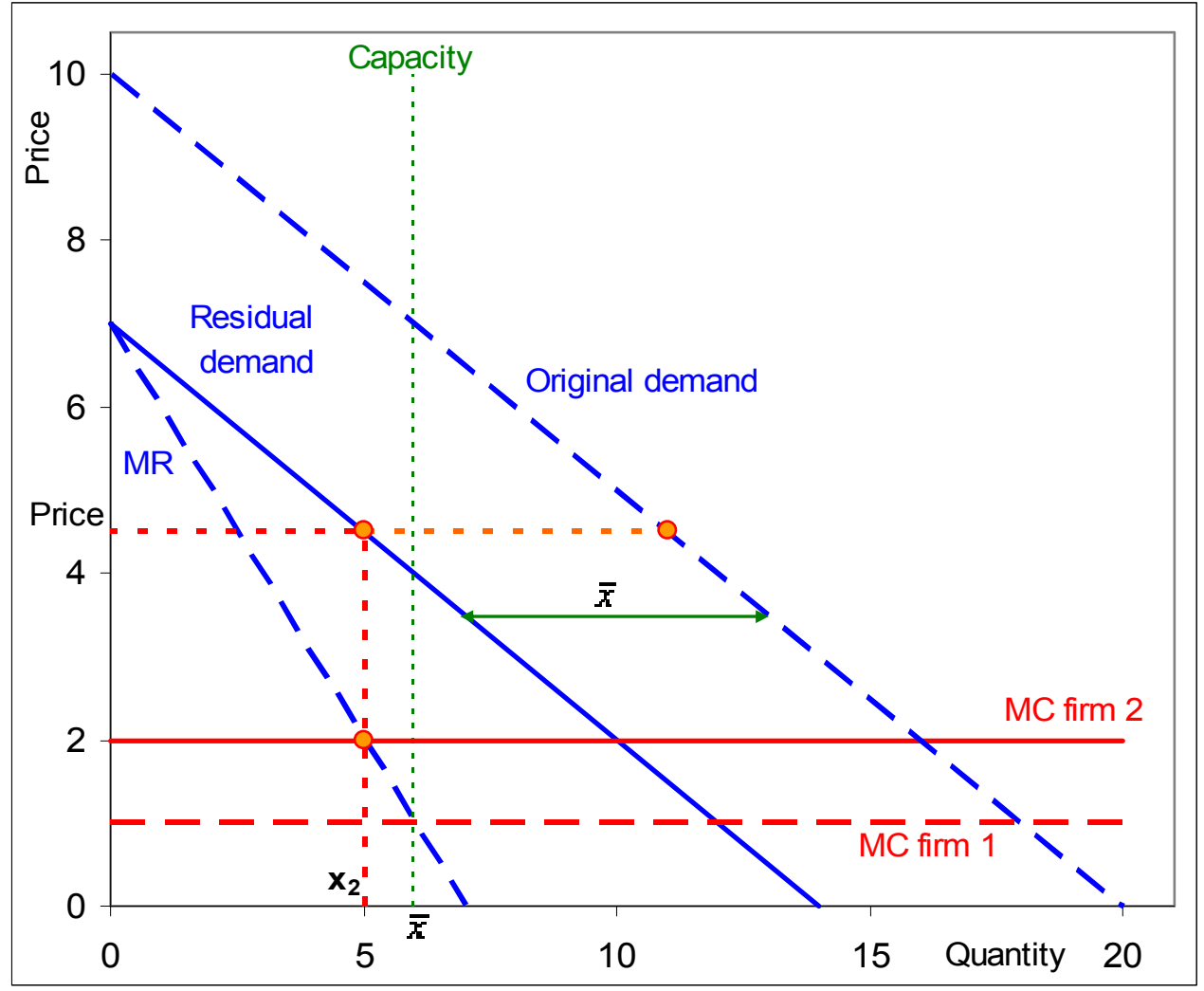


Figure 6: Impact of firm-level capacity constraint on equilibrium
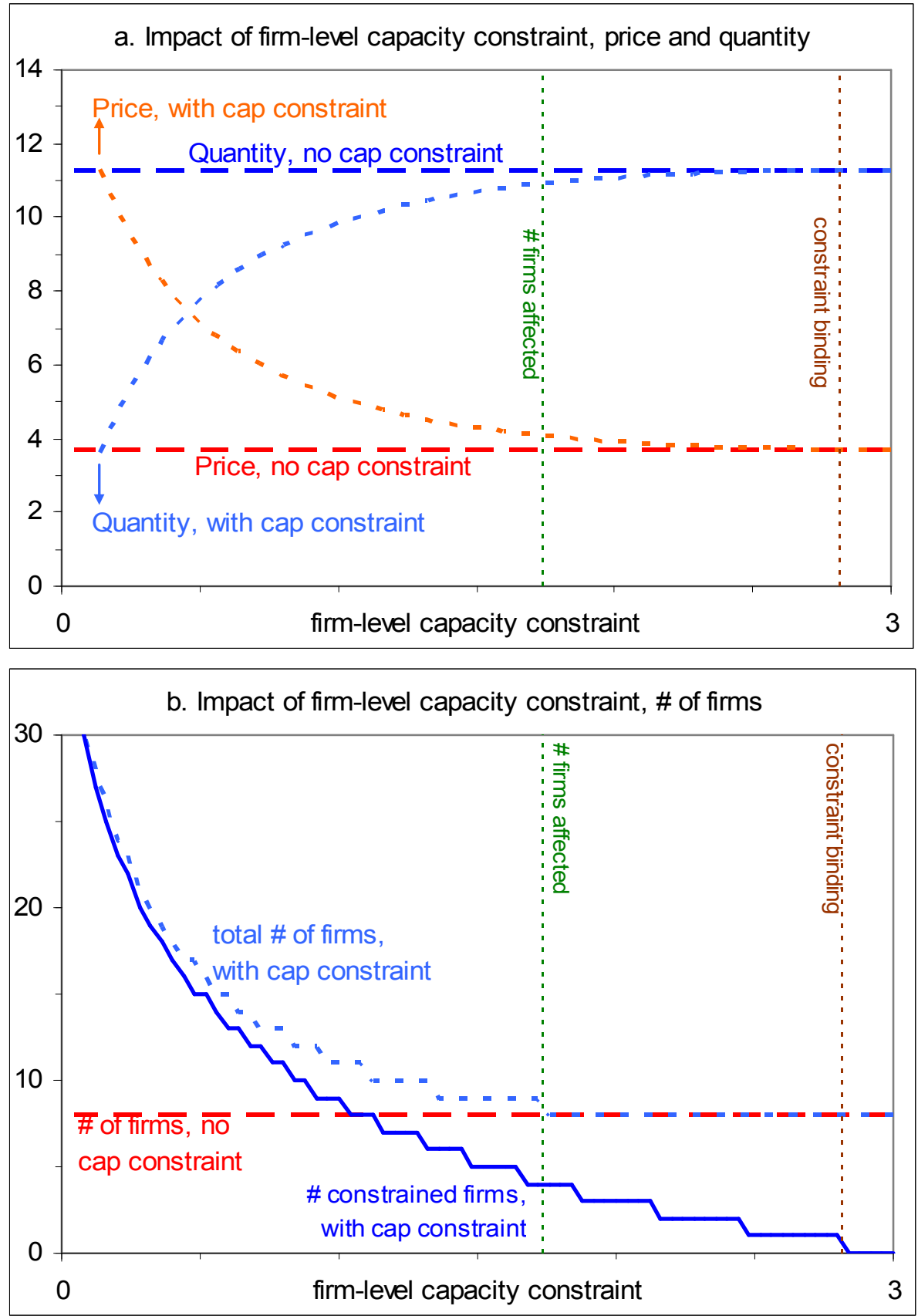

Parameters: $a=15 ; b=1 ; F=0 ; \kappa=0.5 ; \lambda=0.4$. 
Figure 7: Capacity constraints and production

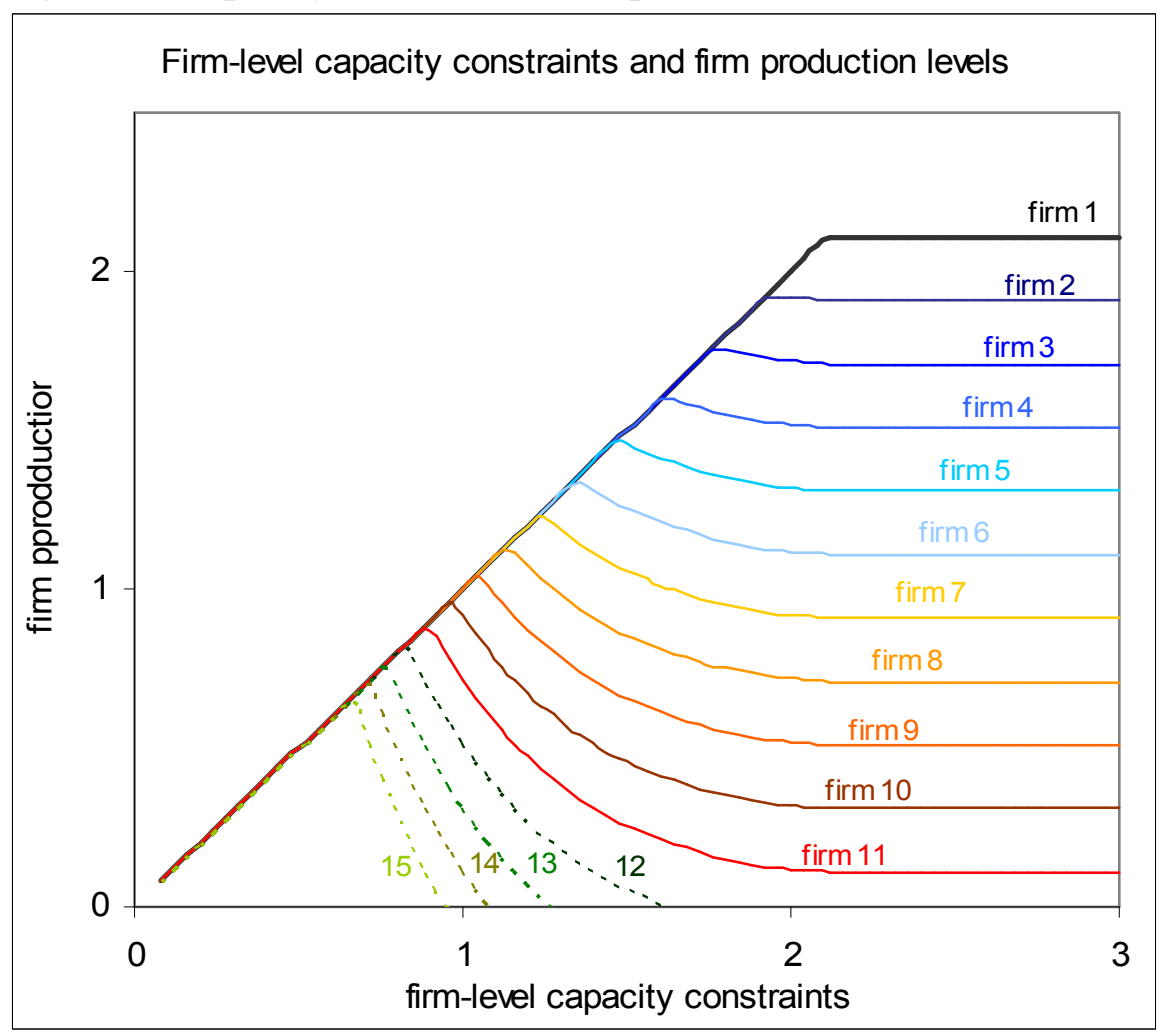

Parameters: $a=15 ; b=1 ; F=0 ; \kappa=0.5 ; \lambda=0.2$; dashed lines indicate firms not viable without capacity constraints. 
Figure 8: Capacity constraints and profits

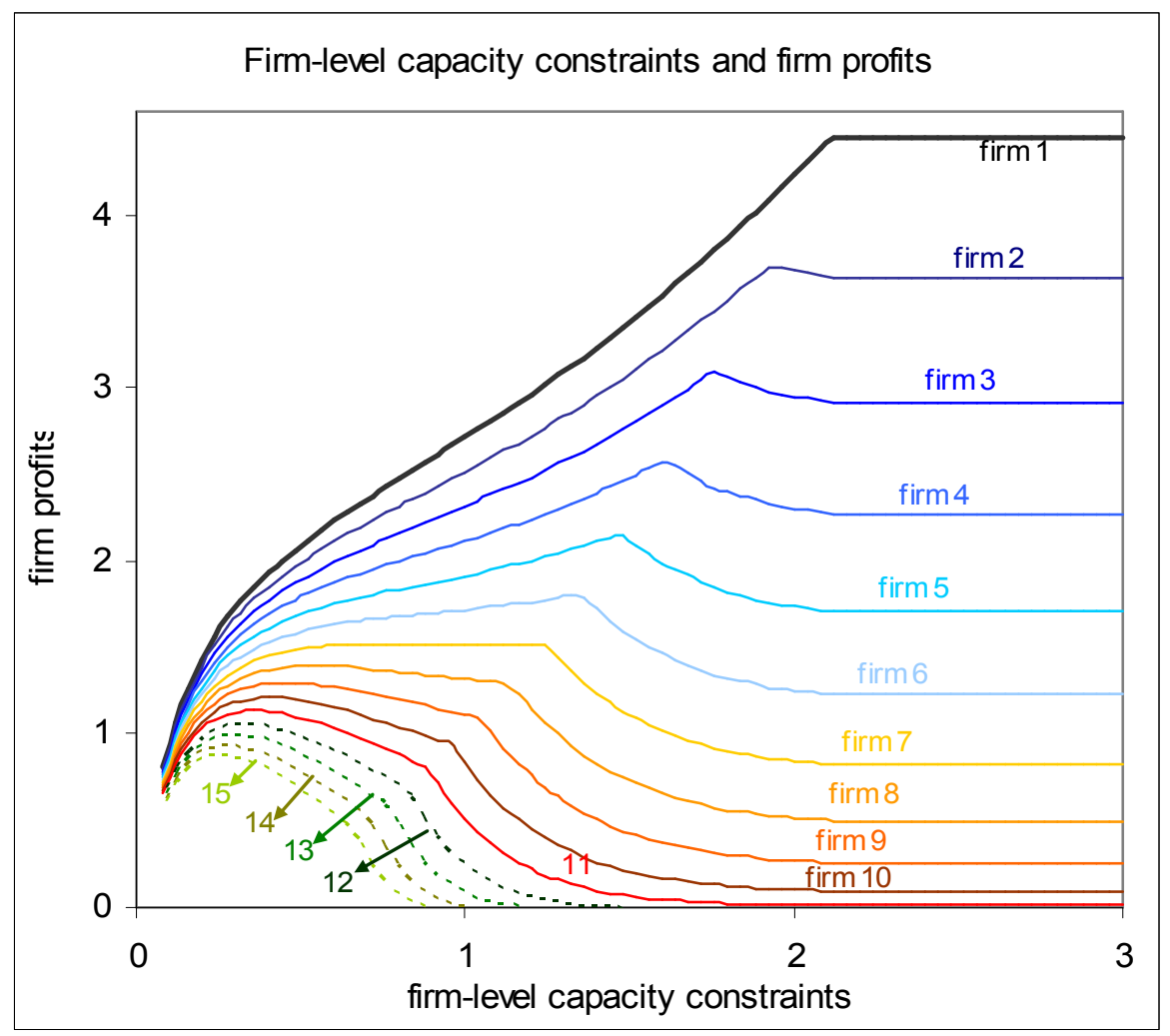

Parameters: $a=15 ; b=1 ; F=0 ; \kappa=0.5 ; \lambda=0.2$; dashed lines indicate firms not viable without capacity constraints. 
Figure 9: Impact of demand parameter $a$ on equilibrium
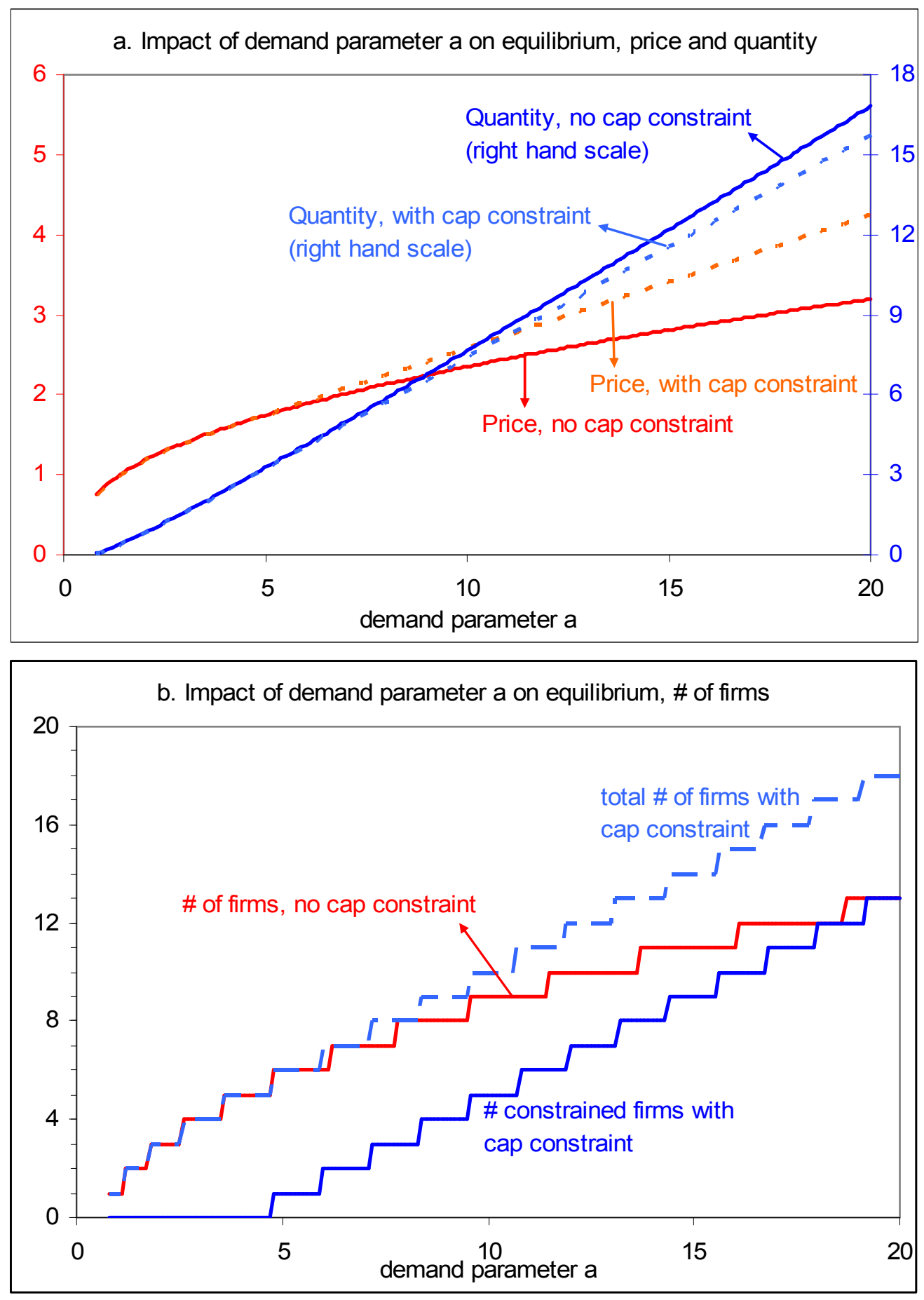

Parameters: $\bar{x}=1 ; b=1 ; F=0 ; \kappa=0.5 ; \lambda=0.2$. 
Figure 10: Impact of inefficiency parameter $\kappa$
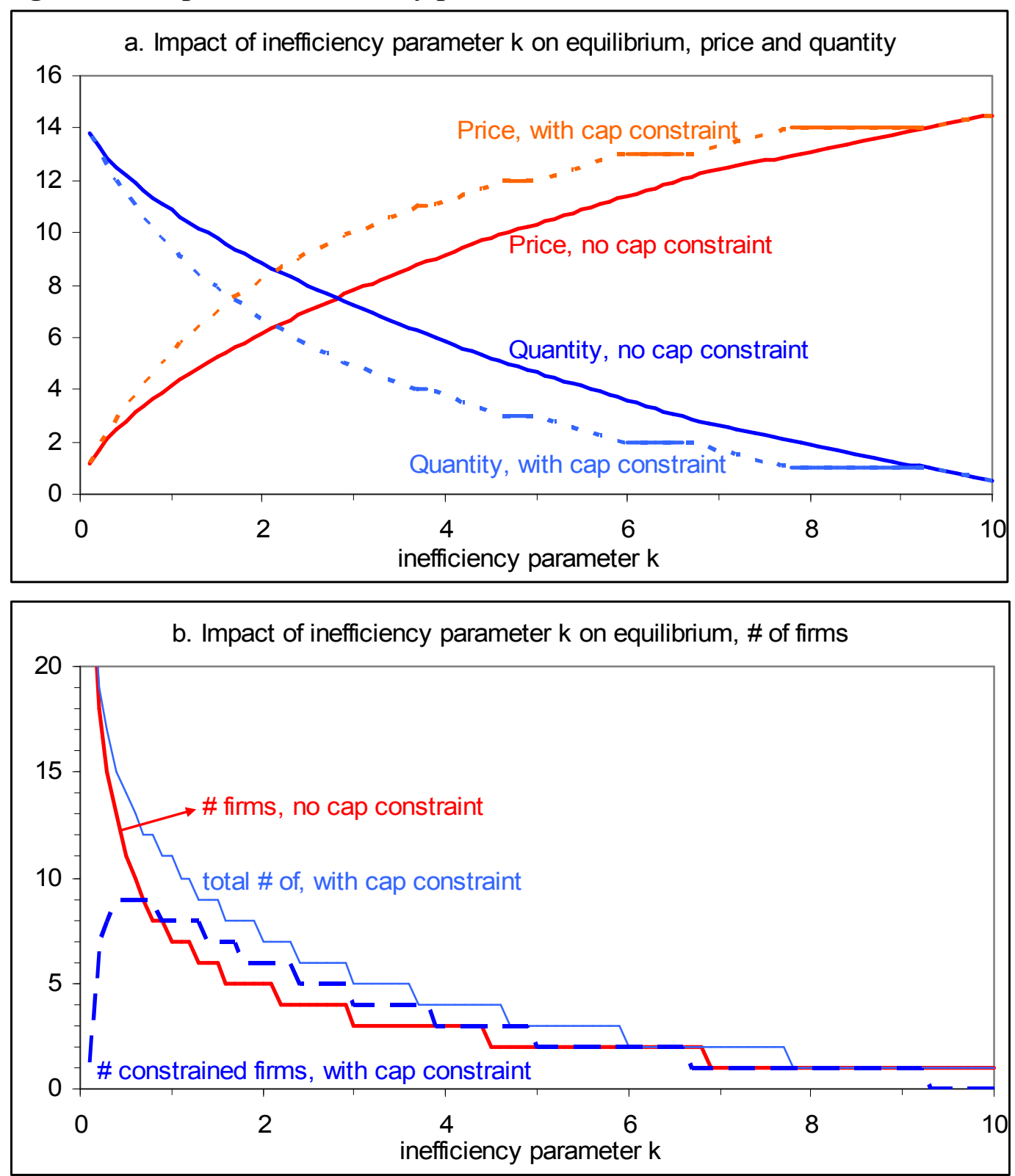

Parameters: $\bar{x}=1 ; b=1 ; F=0 ; a=15 ; \lambda=0.2$. Note that the four horizontal parts indicated by solid sections for price and quantity with capacity constraints in panel a identify sections where all firms active in the market are capacity-constrained. 